\title{
A Human-Centered C2 Assessment of Model and Simulation Enhanced Planning Tools
}

\author{
by Jeffrey T. Hansberger, Randall D. Spain, and Craig Schreiber
}

ARL-TR-6964

June 2014

Approved for public release; distribution is unlimited. 


\section{NOTICES}

\section{Disclaimers}

The findings in this report are not to be construed as an official Department of the Army position unless so designated by other authorized documents.

Citation of manufacturer's or trade names does not constitute an official endorsement or approval of the use thereof.

Destroy this report when it is no longer needed. Do not return it to the originator. 


\title{
Army Research Laboratory
}

Aberdeen Proving Ground, MD 21005-5425

ARL-TR-6964

June 2014

\section{A Human-Centered C2 Assessment of Model and Simulation Enhanced Planning Tools}

\author{
Jeffrey T. Hansberger and Craig Schreiber
}

Human Research and Engineering Directorate, ARL

Randall D. Spain

Old Dominion University 


\section{REPORT DOCUMENTATION PAGE}

Public reporting burden for this collection of information is estimated to average 1 hour per response, including the time for reviewing instructions, searching existing data sources, gathering and maintaining the data needed, and completing and reviewing the collection information. Send comments regarding this burden estimate or any other aspect of this collection of information, including suggestions for reducing the burden, to Department of Defense, Washington Headquarters Services, Directorate for Information Operations and Reports (0704-0188), 1215 Jefferson Davis Highway, Suite 1204, Arlington, VA 22202-4302. Respondents should be aware that notwithstanding any other provision of law, no person shall be subject to any penalty for failing to comply with a collection of information if it does not display a currently valid OMB control number.

PLEASE DO NOT RETURN YOUR FORM TO THE ABOVE ADDRESS.

\begin{tabular}{|c|c|}
\hline $\begin{array}{l}\text { 1. REPORT DATE (DD-MM-YYYY) } \\
\text { June } 2014\end{array}$ & $\begin{array}{l}\text { 2. REPORT TYPE } \\
\text { Final }\end{array}$ \\
\hline 4. TITLE AND SUBTITLE & \\
\hline
\end{tabular}

Tools

3. DATES COVERED (From - To)

2007-2009

5a. CONTRACT NUMBER

5b. GRANT NUMBER

5c. PROGRAM ELEMENT NUMBER

6. AUTHOR(S)

Jeffrey T. Hansberger, Randall D. Spain, and Craig Schreiber

5d. PROJECT NUMBER

5e. TASK NUMBER

5f. WORK UNIT NUMBER

8. PERFORMING ORGANIZATION

REPORT NUMBER

U.S. Army Research Laboratory

ATTN: RDRL-HRM-D

Aberdeen Proving Ground, MD 21005-5425

9. SPONSORING/MONITORING AGENCY NAME(S) AND ADDRESS(ES)

ARL-TR-6964

10. SPONSOR/MONITOR'S ACRONYM(S)

11. SPONSOR/MONITOR'S REPORT

NUMBER(S)

\section{DISTRIBUTION/AVAILABILITY STATEMENT}

Approved for public release; distribution is unlimited.

13. SUPPLEMENTARY NOTES

\section{ABSTRACT}

The Conflict Modeling, Planning, and Outcomes Experimentation Program (COMPOEX) was designed to test the use of multiresolution models (MRMs) in conjunction with the Option Exploration Tool for operational-level planning. The COMPOEX system was evaluated on what products or outcomes it facilitated, how it facilitated those products, the effect it had on understanding, and the results of its use in this 2-week planning event. The output and products that COMPOEX facilitated were evaluated in terms of the time and effort to develop the MRMs and the planning outputs produced. The time and resources required for the development of the MRMs compared favorably with the requirements for nodal network development. The coordination that occurred with COMPOEX showed that it did not restrict collaboration across lines of effort, between leadership and planners, or between military and civilian/government experienced participants. The analyses across each of these areas showed that COMPOEX consistently had positive results and appears to support the planning process in the areas mentioned.

15. SUBJECT TERMS

COMPOEX, planning, operations, multiresolution model, theory of conflict, PMESII, DIME, situation understanding, shared situation understanding, trust, workload, cognitive maps, coordination, Pathfinder, social network analysis

\begin{tabular}{|l|l|l|l|c|l|}
\hline \multicolumn{2}{|l|}{$\begin{array}{l}\text { 16. SECURITY CLASSIFICATION OF: } \\
\text { a. REPORT }\end{array}$} & $\begin{array}{l}\text { 17. LIMITATION } \\
\text { OF ABSTRACT }\end{array}$ & $\begin{array}{l}\text { 18. NUMBER } \\
\text { OF PAGES }\end{array}$ & $\begin{array}{l}\text { 19a. NAME OF RESPONSIBLE PERSON } \\
\text { Jeffrey T. Hansberger }\end{array}$ \\
\cline { 1 - 1 } \begin{tabular}{l} 
Unclassified \\
\cline { 5 - 6 }
\end{tabular} & Unclassified & $\begin{array}{l}\text { c. THIS PAGE } \\
\text { Unclassified }\end{array}$ & UU & 58 & $\begin{array}{l}\text { 19b. TELEPHONE NUMBER (Include area code) } \\
\text { 256-273-9895 }\end{array}$ \\
\hline
\end{tabular}




\section{Contents}

List of Figures $\quad$ v

List of Tables

$\begin{array}{lr}\text { 1. Introduction } & 1\end{array}$

2. Method 4

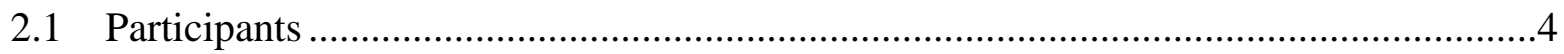

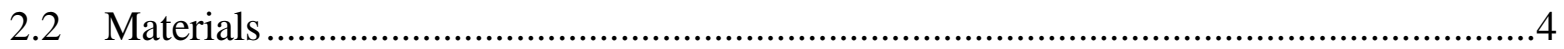

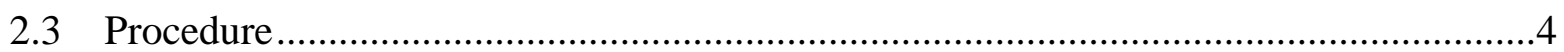

3. Results and Discussion $\quad 5$

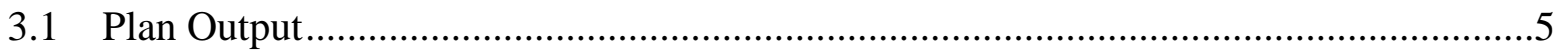

3.1.1 MRM and Theory of Conflict Development .............................................

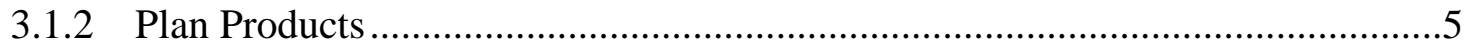

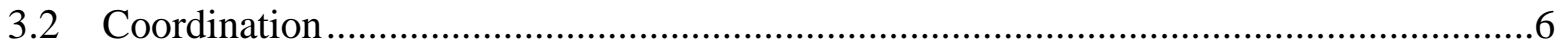

3.3 COMPOEX Tool Effects on Human Performance ..............................................

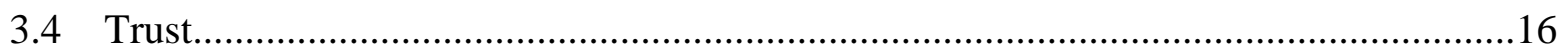

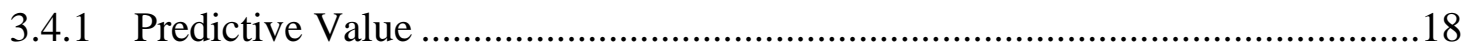

3.4.2 Explorative Value ...............................................................................19

3.4.3 Predictive Value Versus Explorative Value and Usage ................................20

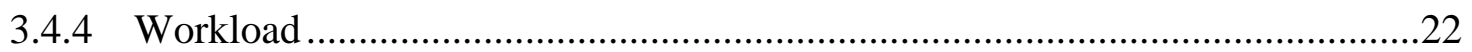

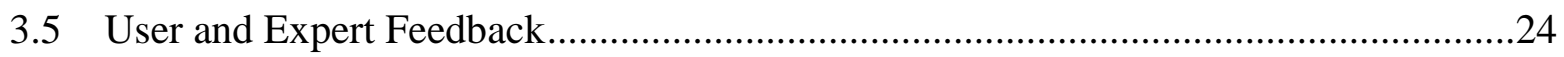

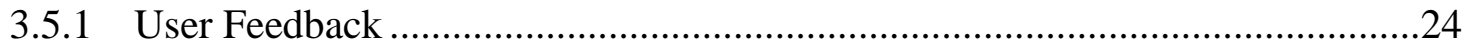

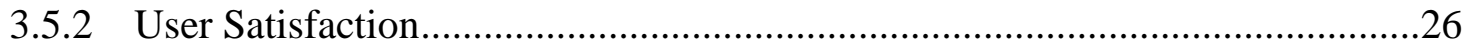

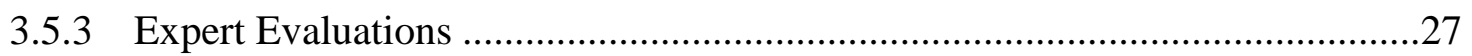

4. Conclusions 29

$\begin{array}{ll}\text { 5. References } & 30\end{array}$

Appendix A. COMPOEX Program Components 33

Appendix B. Trust Questionnaire $\quad 35$ 
Appendix C. Conflict Modeling, Planning, and Outcomes Experimentation Program (COMPOEX) Capability Questionnaire

Appendix D. System Usability Scale

Appendix E. Traditional Planning Capability Baseline Questionnaire

Distribution List 


\section{List of Figures}

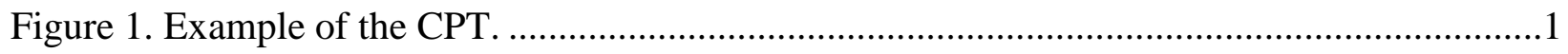

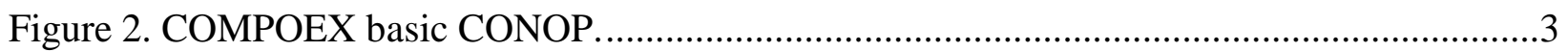

Figure 3. Patterns of communication for the governance line-of-effort team across the first 4 days of the execution week. Governance members are teal, reconstruction is red, security is blue, and yellow-green is strategic cell and "other."

Figure 4. Total time spent in minutes by the governance team interacting with the COMPOEX tool and model support staff over time.

Figure 5. Total time spent by each command group member with the COMPOEX tools over time.

Figure 6. Expert Afghanistan environment knowledge structure.

Figure 7. Understanding over time among the leadership and planning staff groups.

Figure 8. Understanding over time among the military and civilian/government groups.

Figure 9. Degree of similarity between knowledge structures of the military and civilian/government groups over time. Trend line represents a significant positive trend......13

Figure 10. Understanding over time across all participants. The trend line represents a significant positive trend.

Figure 11. Knowledge structures T1 (top) and T4 (bottom) of the Afghan environment across all participants.

Figure 12. Theoretical relationships of trust as a mediating variable between MRM use and increased understanding of the environment.

Figure 13. Trust in the MRMs as a function of participant status. ..........................................17

Figure 14. Trust in the MRMs as a function of status and time.............................................18

Figure 15. Predictive value as a function of planning experience and time. .............................19

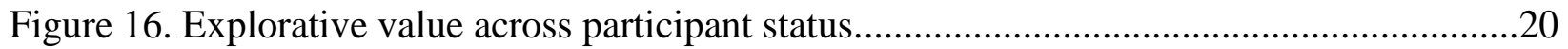

Figure 17. Comparison of explorative value vs. predictive value. ..........................................21

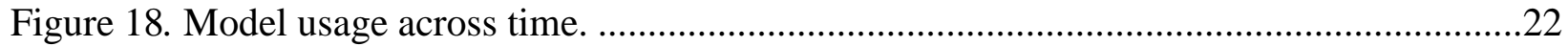

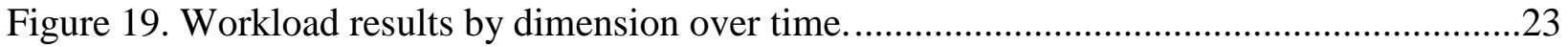

Figure 20. Average scores for each COMPOEX capability item answered by the participants. ..25

Figure 21. User satisfaction scores between civilian- and military-experienced participants for three of the key COMPOEX tools in LOE 2-3.

Figure 22. Expert evaluations between COMPOEX and traditional planning capabilities. 


\section{List of Tables}

Table 1. Concept focus on the "Afghan government" concept for the T1, T4, and referent knowledge structures in figures 11 and 6 (referent).

Table 2. Items that were significantly higher and lower than the neutral score of 3 among participants.

Table 3. Items that were significantly higher among military-experienced participants vs. civilian/government-experienced participants.

Table 4. Capabilities that were evaluated significantly higher for COMPOEX-assisted planning compared with traditional planning. 


\section{Introduction}

The U.S. Defense Advanced Research Project Agency (DARPA) and the U.S. Joint Forces Command (JFCOM) developed a suite of decision support tools to enhance the capability of commanders and staffs to plan and execute effects-based campaigns. The complex environments in which commanders and staffs must operate present such nonmilitary issues as political, economic, social, information, and infrastructure (PMESII). To better assess, understand, and explore the relevant and important issues across these operational dimensions, DARPA and JFCOM have developed the Conflict Modeling, Planning, and Outcomes Experimentation Program (COMPOEX) system to support the commanders and staffs. Multiple limited objective experiments (LOEs) were conducted to test and assess the progress and effectiveness of one or more of the tools. This report describes the LOEs addressing the effects on command and control (C2) and planning for the Option Exploration Tool (OET) and the Campaign Planning Tool (CPT). The COMPOEX LOE 2-3 was designed to test the use of multi-resolution models (MRMs) in conjunction with the OET and CPT for operational level planning using the effectsbased operations approach. The OET and the CPT are the primary COMPOEX interfaces with the MRMs. The CPT provides a timeline to designate the actions, effects, resources, and objectives for the plan (figure 1). These plan elements provide input into the MRMs and designate which aspects of the plan to be simulated. The results of the simulation can then be examined using the OET.

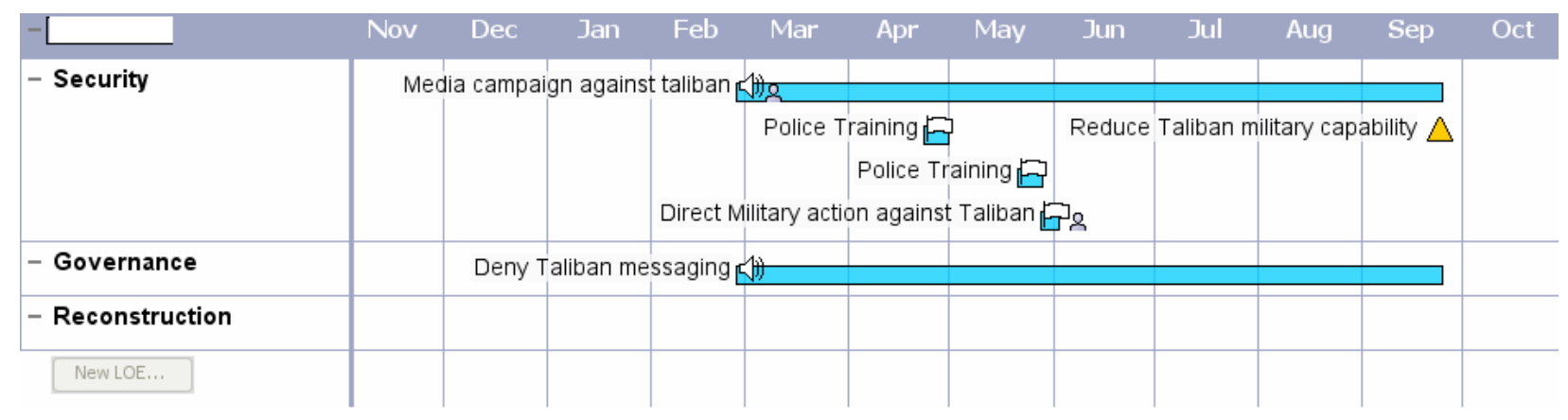

Figure 1. Example of the CPT.

The OET consists of several "views" of the simulated plan that represent the results of the simulated run given the plan inputs provided through the CPT. The views include the (1) outcome view, (2) graph view, (3) panel view, (4) exploration analysis view, and (5) model operations view (appendix A). The outcome view presents the events or actions that exceed a predefined threshold while the graph view visually presents the simulated results across time for the selected variables. The panel and model operations views show the relationships between the variables while the exploration analysis view illustrates the variables influencing and responsible for the change in the targeted variable as well as what variables it in turn affects. 
The planning environment that was used for this event was the Afghanistan region, with the objectives of developing multiple lines of effort (e.g., security, governance, rule of law) and supporting effects to improve regional stability of the Afghanistan region. A line of effort is a PMESII-related area of effort that needs to be planned and coordinated to achieve the objectives. The basic concept of operation (CONOP) established for using COMPOEX is illustrated in the following six steps (COMPOEX, 2007), with an emphasis on steps 4-6 for this event.

1. Mission Analysis - Decomposition of the commander's intent into key elements, dates, constraints and restraints, etc. Identify the actors, issues and sources of conflict; develop a theory of the dynamics between actors and the drivers of conflict, competition, and cooperation among actors.

2. Situation Assessment - Review of the MRM and baseline estimates of projected PMESII dynamics without any planned exogenous actions.

3. Strategy Development - Identification of objectives on a timeline. Articulate specific desired ends, objective, and purpose of the mission.

4. Plan Development - Insertion of specific planned diplomatic, information, military, economic (DIME) actions along lines of effort.

5. Run Simulation - Conduct a run of the simulation to produce PMESII effects of the scheduled DIME actions across all model components. Apply the actions identified in the courses of action (COAs) to system models that synthesize the expected effects from combined actions. Observe first-order and higher order effects; identify critical interactions and potential unintended consequences. Test and validate plan and/or plan fragments by execution of the plan within the full PMESII model simulation.

6. View Effects - The user views the effects of the candidate campaign on the targeted systems. Apply these observations of the actual outcomes of individual actions, and aggregate outcomes to update and refine the models used in analysis and wargaming.

Figure 2 shows the six steps of a CONOP for COMPOEX. 


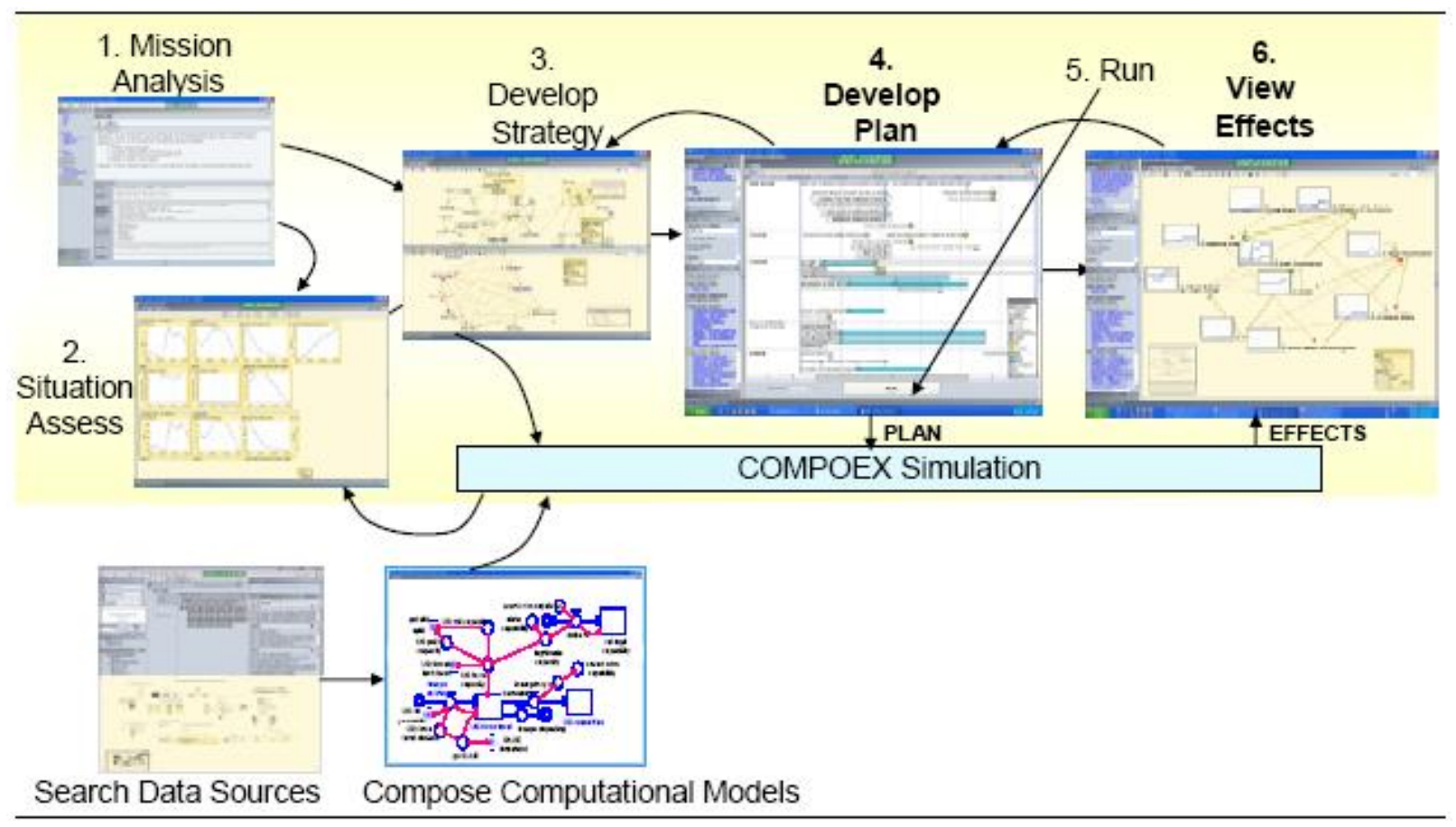

Figure 2. COMPOEX basic CONOP.

The participants were assigned to three primary planning groups, each of which was responsible for the following lines of effort: (1) reconstruction, (2) governance, and (3) security. The assignment of participants to each of these lines of effort was based roughly on the participants' past experience and background. Each of these lines-of-effort planning teams had a military or civilian lead experienced in that particular area. In addition to the three lines-of-effort teams, there was a strategy cell that convened periodically throughout the event to discuss strategic and overarching issues.

The enhanced ability of COMPOEX to simulate a plan and the various components within a plan (e.g., actions, effects) is expected to positively stimulate the thought processes of the commander and planning staff. The exploration of various "what-if" scenarios and plans through simulation allows commanders to further develop their understanding and test various theories of conflict and effects of key perceived relationships across PMESII elements. This increased capacity to explore the environment and situation through the MRMs and examination of the results through the OET is hypothesized to improve planning effectiveness and understanding. It is also hypothesized that MRMs of sufficient validity and fidelity can be developed to facilitate planning with limited time and resources. 


\section{Method}

\subsection{Participants}

There were 25 active participants for LOE 2-3, consisting of eight senior mentors and 17 planners. Fifteen of the players had military background and experience while 10 of the players had a nonmilitary (government or civilian) background and experience. The total number of years of military experience (412) slightly outweighed civilian experience (336.5). Overall tactical planning experience (247) was most prevalent, with significant amounts evident for the operational (201) and strategic (130) levels. Experience in the Afghanistan environment was limited - a total of 31.5 years of experience across all participants. This experience was spread among 13 participants, with a maximum of 7 years of experience for one participant.

\subsection{Materials}

All participants received the read-aheads on the Afghanistan region and the Theory of Conflict (ToC) work that had been completed prior to LOE 2-3. Participants had access to the COMPOEX system using laptop computers during the LOE. Multiple overhead digital projectors were available to display images on screens in the LOE area.

\subsection{Procedure}

LOE 2-3 was a 2-week event with training and execution components. The first week was dedicated to training participants on the COMPOEX system, and the second consisted of execution set week in the Afghanistan region using COMPOEX. The execution week began with the development of 10 effects by the three line-of-effort teams (reconstruction, governance, and security. During the execution week, the line-of-effort planning teams developed the individual effects into a single plan for their line of effort. The teams continued refining the plan by integrating the three lines-of-effort plans into a single integrated plan by the end of the event. Resources were allocated to additional effects and lines of effort as needed throughout the execution week. The strategy cell and the leaders of each line of effort made the determination for these additional effects and lines of effort. 


\section{Results and Discussion}

\subsection{Plan Output}

\subsubsection{MRM and Theory of Conflict Development}

The development of the MRMs was done prior to the LOE 2-3 and amounted to approximately 600 man-hours over a 3.5-month period. This effort consisted of 10 individuals working partand full-time. The comparative planning cell also had 10 individuals developing their nodal network (network of relevant people, places, and things) and database. The total time spent developing it when LOE 2-3 occurred was 5 months or approximately 8000 man-hours.

In conjunction with the time spent developing the MRMs, a ToC workshop was conducted in May 2007. A ToC identifies and defines the relevant elements and structure of a PMESII system along with the causal explanation of the system's basic behaviors (COMPOEX, 2007). This 2-day $\mathrm{ToC}$ workshop collected expertise on the Afghanistan region from military and civilian government and nongovernment agencies to develop multiple possible Afghanistan-related ToCs. Approximately 145 man-hours of Afghanistan expertise was applied to the development of ToCs and was included into the building of the MRMs. The total amount of man-hours including the ToC workshop was 745. The amount and access to Afghanistan subject matter experts (SMEs) by the comparative planning cell is unknown.

\subsubsection{Plan Products}

The participants comprising the command and staff groups developed a number of products as they engaged in the execution week with the COMPOEX system. Actions in a plan are one of the primary planning components that the COMPOEX system allows the planner to explore. This is done by defining the action(s) within the CPT, and is simulated against the MRMs to allow the commander and/or staff to examine the effects of their actions. A total of 592 unique actions were defined and explored by the command and staff groups for this event over the 5-day event period.

The material and domain used during the execution week was also used during part of the training week. The inclusion of the actions created and examined during the training period, an additional 71 actions, totaled 663 actions during the training and execution weeks. As a general reference point, the Standing Joint Force Headquarters "starter kit" of actions used by the comparative planning cell consisted of 150 actions, which have only been slightly modified.

Ten effects were developed and integrated into the final plan during the training and execution weeks. Six additional effects were initiated across the three lines of effort, and one additional line of effort was created as the issue of strategic communications appeared to have a prominent effect across each of the existing lines of effort. The original 10 effects were developed in the 
span of the 5-day event and integrated into a single plan across four lines of effort that included the reconstruction, governance, security, and strategic communications lines of effort, while the additional six effects were being developed concurrently beginning on day 8 . The comparative planning cell had developed five effects over a period longer than 2 months at the time LOE 2-3 occurred. The efficiency of the COMPOEX team can be described by considering the number of effects (16) initiated during the number of man-hours used for their development. The total manhours during the execution week was 1000 ( $40 \mathrm{~h} \times 25$ participants), which is 62.5 man-hours per effect.

\subsection{Coordination}

The plan output was produced by the participants during the execution event. This section will focus on the processes and interaction patterns that were employed. Traditional statistical analysis complemented by social network analysis was used to analyze the patterns of interaction.

Social network analysis is based on network theory, which uses graphs as a representation of symmetric or asymmetric relations between discrete objects (Scott, 2000). The graph is a mathematical structure used to represent pair-wise relations between objects. Placed within a social context of humans and their interactions, a social network is a set of individuals (i.e., nodes) connected through social interactions like face-to-face or email communication (i.e., links). The analysis of these social networks consists of a family of relational methods to systematically uncover patterns of interconnectedness.

The general patterns of interaction will be described for the governance line-of-effort team, as it currently is the most complete data set among the lines of effort and included the commander as its lead. Figure 3 displays the social network graphs for the first 4 days of the execution week. The last day was excluded from this analysis because the participants were primarily working on preparations and execution of the final brief and the event review. The nodes in the network graphs are color coded to represent members of each of the lines of effort. Days 1 and 2 represent few interactions outside the governance team, as indicated by only one link to the security team and four links with the reconstruction team during day 1. Day 2 followed a similar pattern with only three links with the reconstructions team. For both days, P22 is a critical bridge between the governance and reconstruction teams. Day 3 represents a day of primarily internal work by the governance group with only one link to the security team. The density of the network also suggests that communication was focused between a few individuals that formed a communication triad (P15, P16, and P17), comprising $92 \%$ of the communication by the governance team that day. Day 3 appears to be the quiet before the storm, as Day 4 shows a flurry of communication activity both internal and external to the governance team. As figure 3D shows, there are multiple links to both the security and reconstruction teams, as day 4 represented the primary merging effort across the lines of effort. 


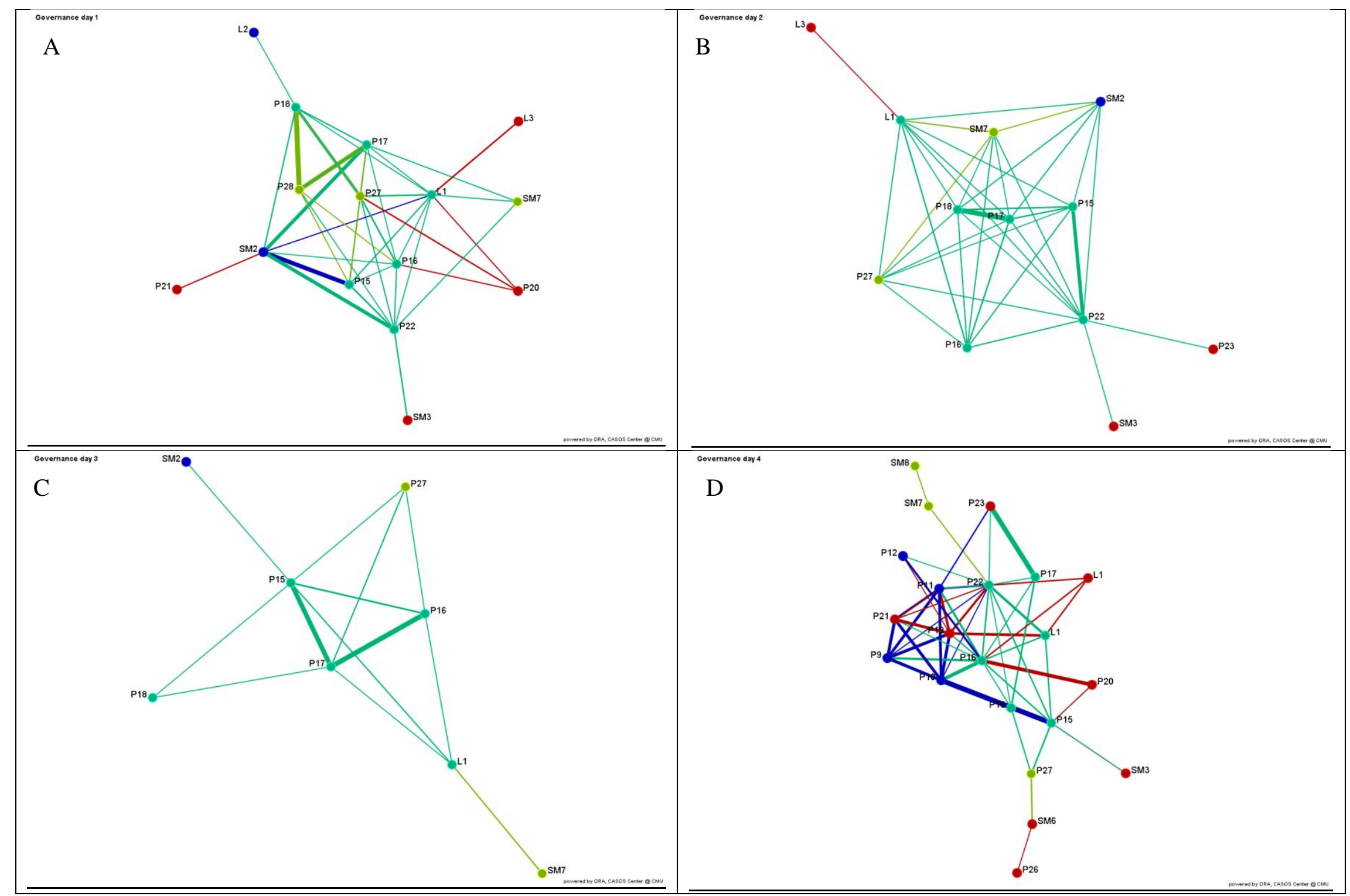

Figure 3. Patterns of communication for the governance line-of-effort team across the first 4 days of the execution week. Governance members are teal, reconstruction is red, security is blue, and yellow-green is strategic cell and "other." 
Further examination of the patterns of interaction collected through observational techniques within the governance line of effort also provided information on the reliance of the governance team on the COMPOEX tool and model developers. All interactions with the COMPOEX tool and model developers that attended LOE 2-3 in a support role were coded together and represented as the P27 node in figure 3A-D. Day 1 shows a strongly central role and reliance on the tool support staff, as P27 is a central node in the network with many communication ties to other governance team members. As time progresses from day 1 through 4 , the position of the support staff (P27) gradually drifts to the periphery of the communication network, which represents a declining reliance on the support staff for the team to efficiently function with the COMPOEX system. This trend in the communication interactions was supported by the reduction of total time spent in communication with the COMPOEX tool and model support staff (figure 4). Both of these findings are important because of the need of the COMPOEX tool to be independent of a large support staff and easy to use as it is transitioned to field settings.

COMPOEX Tool Support Interactions

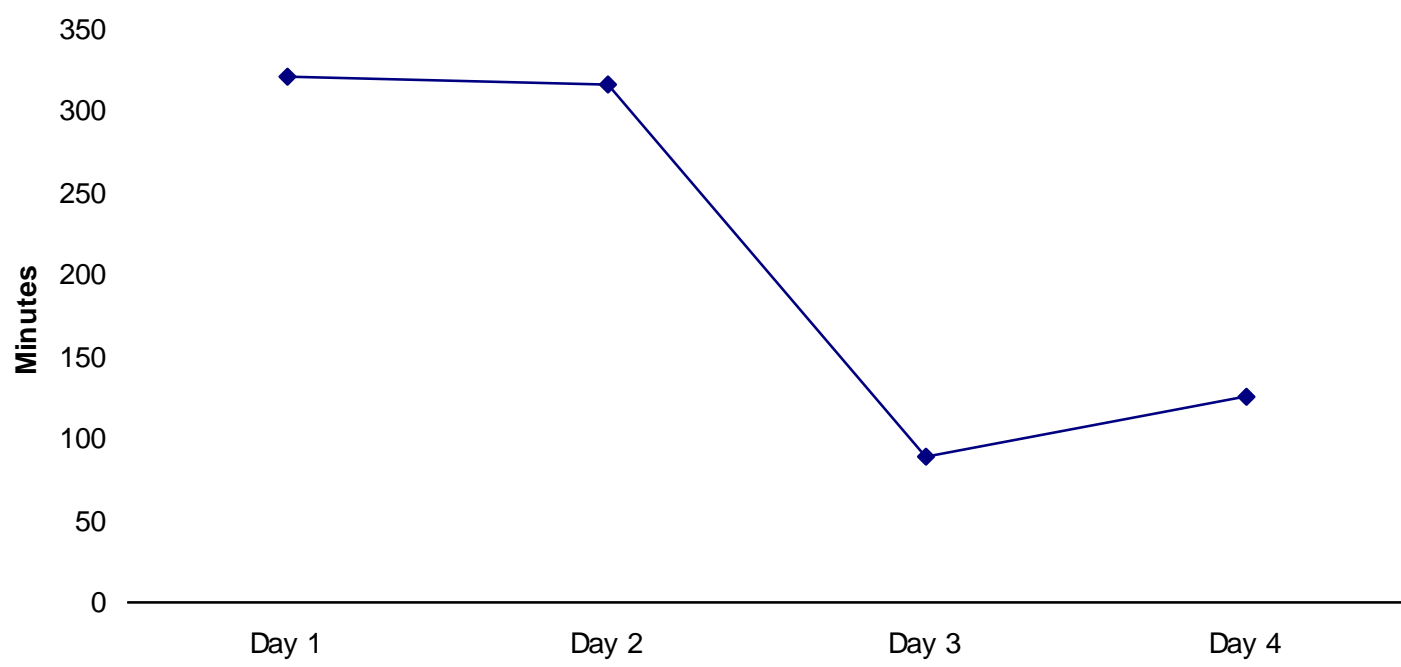

Figure 4. Total time spent in minutes by the governance team interacting with the COMPOEX tool and model support staff over time.

Detailed interactions were recorded for each of the three members of the command group, which consisted of the commander and his two deputies. Each member of the command group directed the actions of the three primary lines of effort (reconstruction, governance, and security). The interactions recorded included those with members of the planning teams (internal and external to their line of effort) and those with the specific COMPOEX tools used. The dynamic interactions by the three members of the command group were examined and analyzed using the Social Network Image Animator (SoNIA). The network illustration showed interactions by the command group with the tools decreased as interactions with the planning team members increased (video available upon request). 
The negative trend in COMPOEX tool usage by the command group is confirmed through an analysis of overall time spent across all the tools over time (figure 5). As evident in the SoNIA analysis, there are individual differences evident among tool usage but the decrease in tool usage from each of the command group members shows their transition from hands-on tool use to a more hands-off command orientation. This pattern of interactions represents a $\mathrm{C} 2$ shift from a focus on the tool to a focus on the planner who is using the COMPOEX tools to support their plans and conclusions.

\section{COMPOEX Tool Use Among Leadership - Total Time}

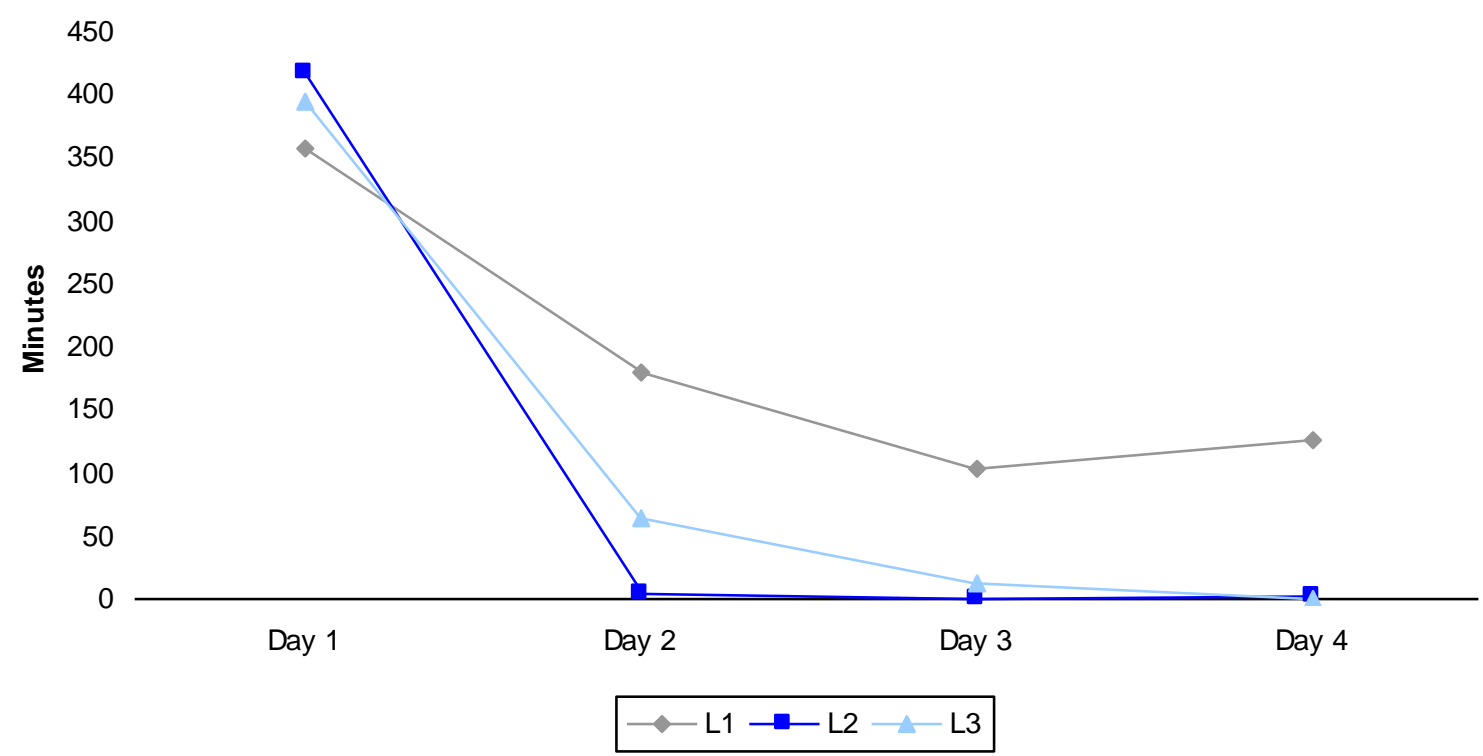

Figure 5. Total time spent by each command group member with the COMPOEX tools over time.

\subsection{COMPOEX Tool Effects on Human Performance}

The two previous sections presented the results of what the participants produced during the event (plan output) and how they produced those products (coordination). This section will present the results of both on human performance effects regarding understanding, workload, and trust in the MRMs.

Gilbert and Troitzsch (2005) succinctly and accurately summarize the primary purpose of modeling and simulation: "Simulation is the development of explanations rather than the prediction of specific outcomes" (p. 12). This is the primary purpose of the MRMs within COMPOEX, as the MRMs attempt to facilitate the development of explanations and help enhance understanding of the operational environment. The COMPOEX MRMs and models or simulations in general can improve the explorability of the target domain by creating the ability to experiment with different options related to the domain. It is through this experimentation process that humans learn about their environment beginning from childhood (Siegler, 2005) and 
continuing through adulthood (Norman, 1988). This section will investigate whether or not the COMPOEX MRMs enhanced the explorability of the Afghanistan environment by improving understanding.

Understanding was measured through elicitation and analysis of individual and group knowledge structures using the Pathfinder methodology and analysis (Schvaneveldt, 1990). Pathfinder is a knowledge elicitation technique that represents domain specific knowledge underlying human performance. Pathfinder uses pairwise proximity estimates for a set of concepts and generates a network structure where the concepts are nodes and the relations between concepts are links in the network structure. Closely related concepts are represented by their proximity to one another in the Pathfinder knowledge structure.

Pathfinder has been in use for more than 20 years to represent knowledge structures of categories (Rubin, 1990), scripts (Durso and Coggins, 1990), room schemata (Schvaneveldt, 1990), and problem-solving schemata (Dayton et al., 1990). It has also been used to identify novices from experts in the domains of air combat flight maneuvers (Schvaneveldt et al., 1985), computer programming (Cooke and Schvaneveldt, 1988), and classroom learning (Goldsmith and Johnson, 1990). These studies have indicated that Pathfinder networks represent knowledge structures in a meaningful way; it identified expert and novice pilots with over 90\% accuracy (Schvaneveldt et al., 1985) and accounted for 55\% of the variance in students' final course points (Goldsmith and Johnson, 1990).

An Afghanistan expert knowledge structure (figure 6) from a former special adviser to the U.S. embassy in Kabul was elicited and used as the comparison basis for all subsequent analyses. Improved similarity over time with this expert referent knowledge structure represents improved understanding and learning. 


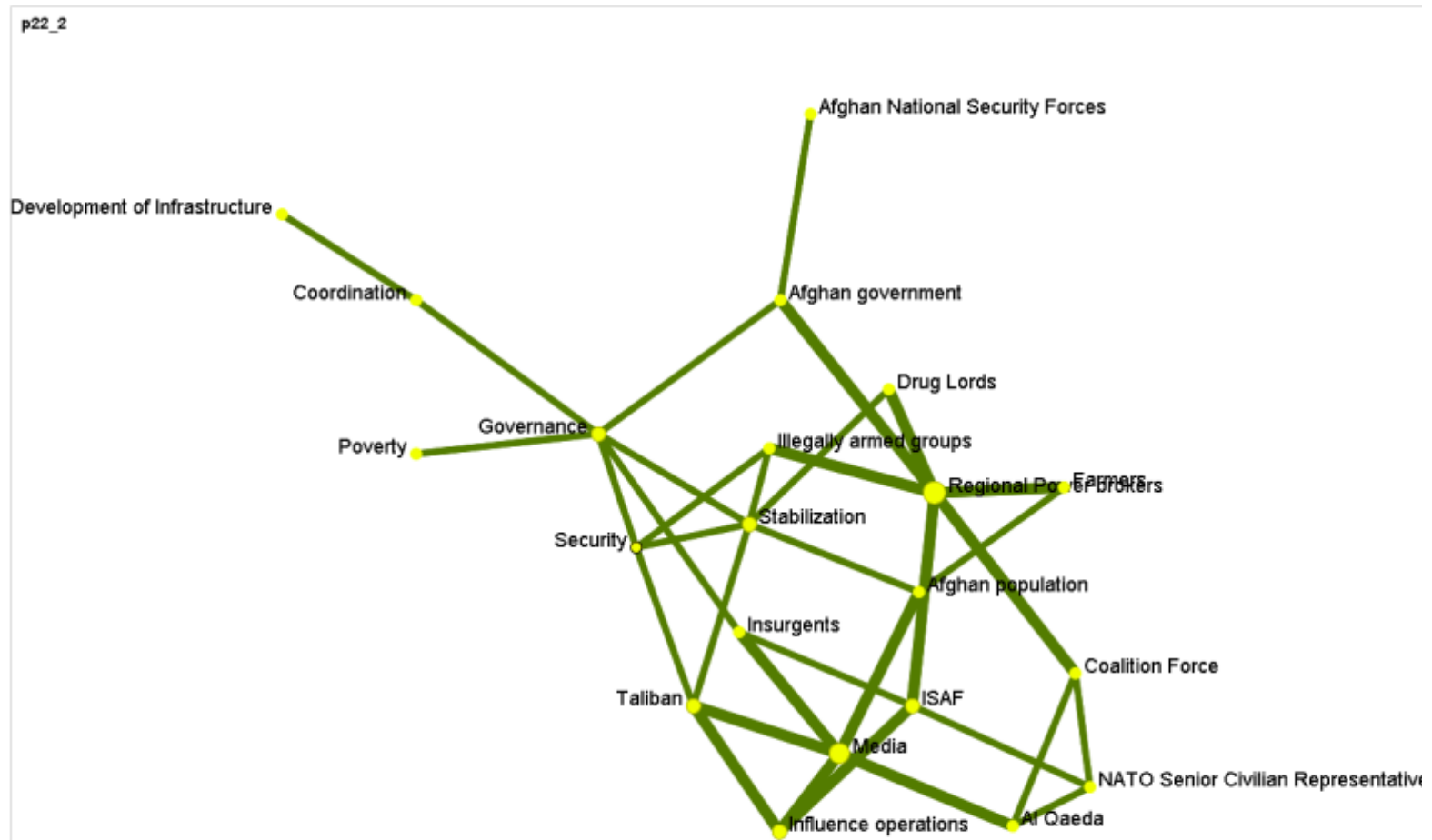

Figure 6. Expert Afghanistan environment knowledge structure.

The effect of using COMPOEX and its supporting MRMs was examined across several groupings that occurred during LOE 2-3. The first that will be addressed is between the leadership and planning staff groups. The leadership group consisted of the three leaders, each directing their line of effort, and the planning staff consisted of the leaders' supporting staff. The knowledge structures were measured on the Wednesday and Friday of both the training week and the execution week. An analysis of similarity with the expert referent or the correspondence of links between the leadership and staff groups with the expert referent knowledge structures shows a general positive trend for both the leadership and staff groups over time (figure 7). This increase in similarity with the expert referent suggests that both groups are improving their understanding of the Afghanistan environment as they interact with the COMPOEX system during the planning process. There is no evidence that suggests that COMPOEX is affecting the leadership and planning staff groups differently. 
Leader \& Staff Similarity with Expert Referent

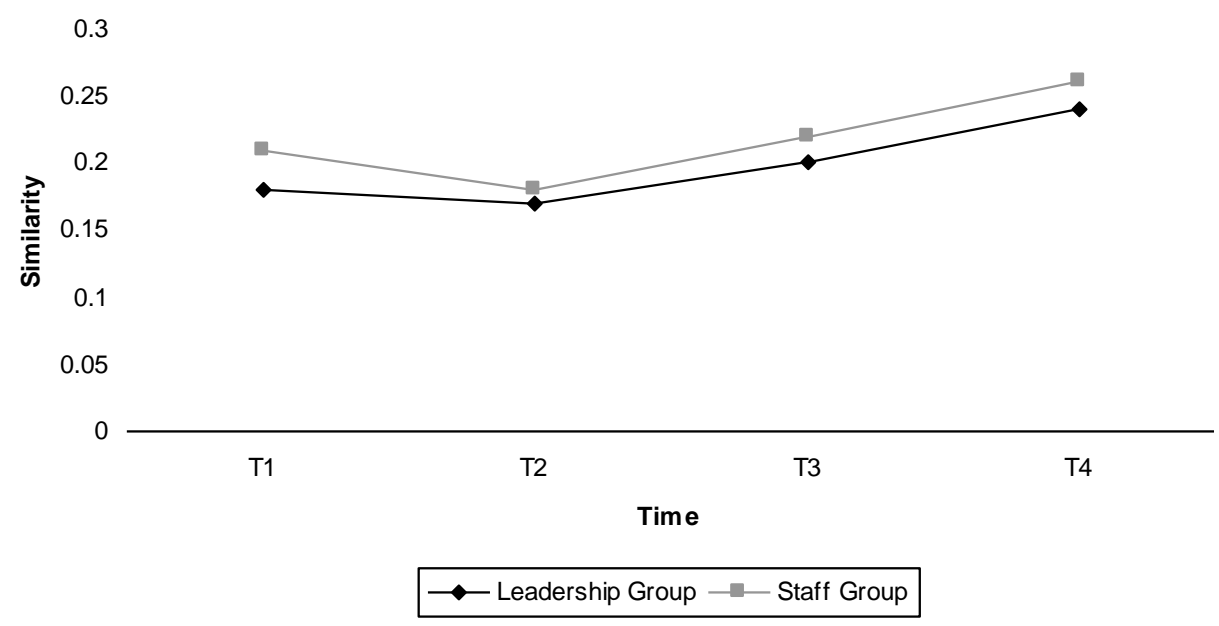

Figure 7. Understanding over time among the leadership and planning staff groups.

The next grouping examined is between the participants with military and civilian/government background and experience. There were 15 participants with military experience and 11 with civilian/government experience. As with the leadership and staff results, similar patterns emerge between the military and civilian groups, as their understanding appears to have similar general positive trends (figure 8). There is also no evidence suggesting that COMPOEX is affecting the military and civilian/government personnel any differently in their ability to improve understanding over time. In fact, when the similarity between the military and civilian groups is examined, they are increasing over time to such a degree that there is a statistically significant positive trend $\left(R^{2}=.90, p=.05\right)$ even though the sample over time is quite limited (figure 9). This suggests that understanding is improving for both the military and civilian personnel and shows that their shared understanding is also improving over time. 


\section{Military \& Civilian Understanding Over Time with Expert Referent}

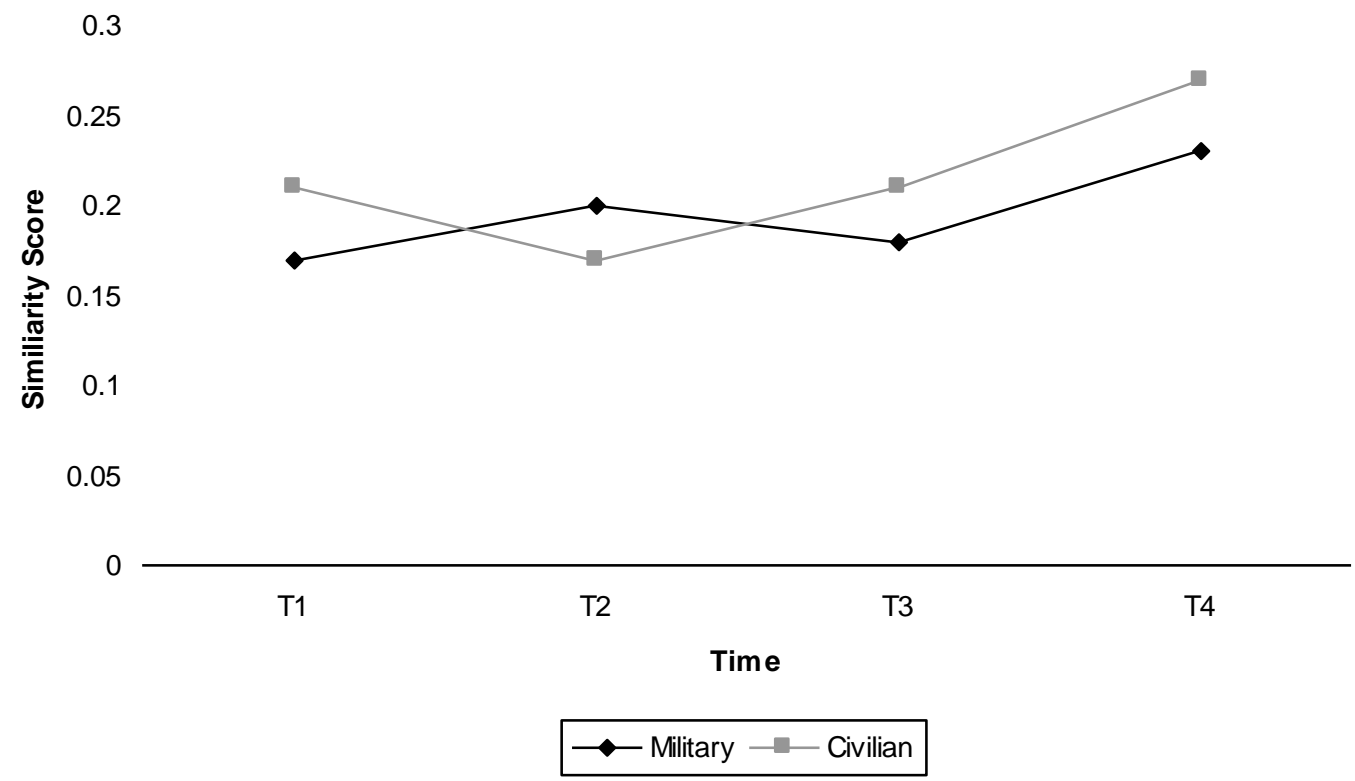

Figure 8. Understanding over time among the military and civilian/government groups.

\section{Military \& Civilian Shared Understanding Over Time}

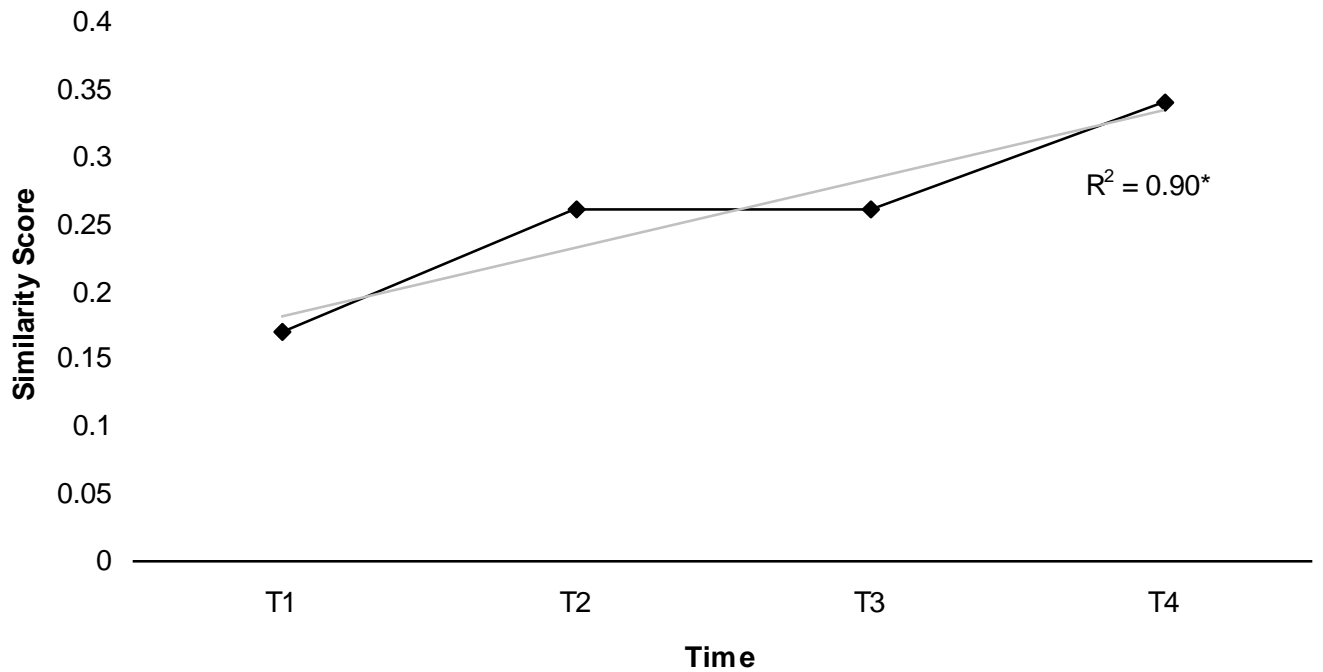

Figure 9. Degree of similarity between knowledge structures of the military and civilian/government groups over time. Trend line represents a significant positive trend. 
The overall understanding results across all participants showed a significant positive trend over time $\left(R^{2}=.90, p=.05\right)$ (figure 10$)$. This suggests that the COMPOEX system had a positive influence on improving understanding among the users. These results are suggestive because there was not an experimental control for the effects of participant interaction and discourse. The results discussed suggest no significant differences in understanding between the leadership and planning staff or the military and civilian groups. Note that knowledge structures from members of the comparative planning cell were collected before LOE 2-3. The comparative planning cell similarity score with the expert referent is illustrated in figure 10 , and is similar to the starting point of the participants in LOE 2-3. The comparative planning cell had a collective 22 years of System of System Analysis experience across the PMESII areas, and had been engaged in supporting Afghanistan related missions for 4 weeks. In the 9 days between the first and last measure for the participants of LOE 2-3, they nearly doubled their similarity score, reflecting an improved understanding of the Afghanistan environment.

\section{Similarity of Overall Understanding with Expert Referent}

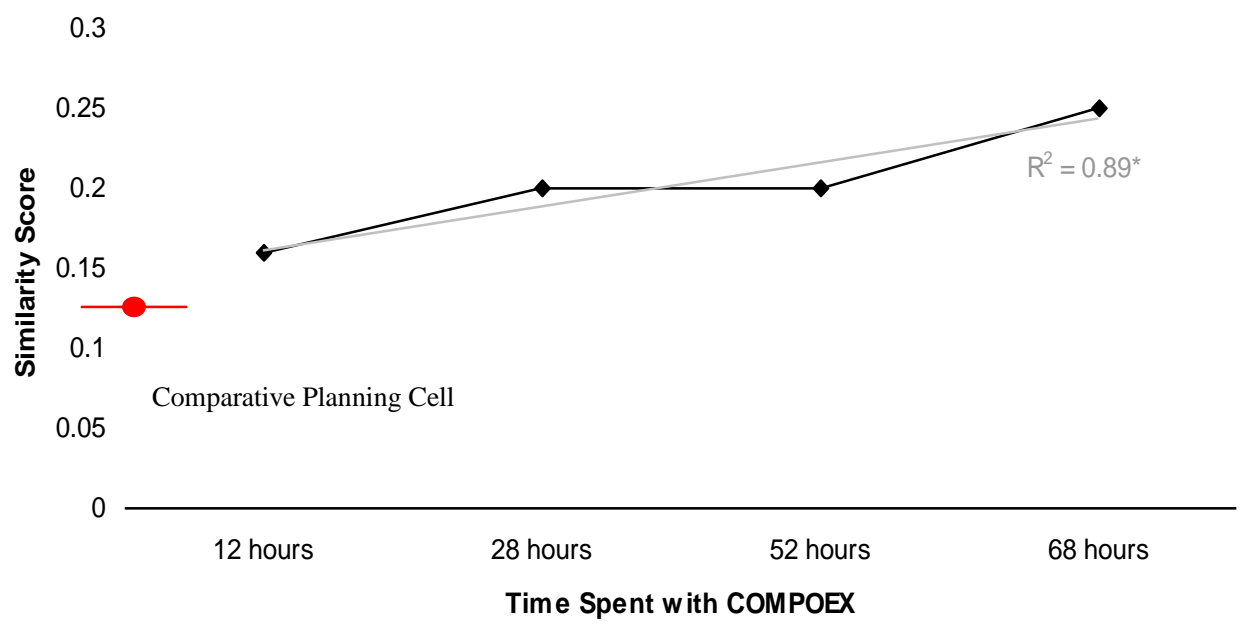

Figure 10. Understanding over time across all participants. The trend line represents a significant positive trend.

Qualitative changes in the overall knowledge structures are evident by comparing the knowledge structure at T1 (day 2) and T4 (day 9) (figure 11). The concepts that are the most highly connected concept within the knowledge structure are typically related to their level of importance. For T1, it is the "Security" and "Afghan government" concepts. The highest degree centrality concepts at T4 are the same with the addition of the "ISAF" concept. Further examination of the knowledge structures reveals that even though some of the same key concepts are the same from T1 to T4, they are defined differently. Examination of the direct links to each of these concepts shows some of these differences for the "Afghan government" concept (table 1). Similar differences are evident for the other concepts and can be further investigated by comparing the knowledge structures. 

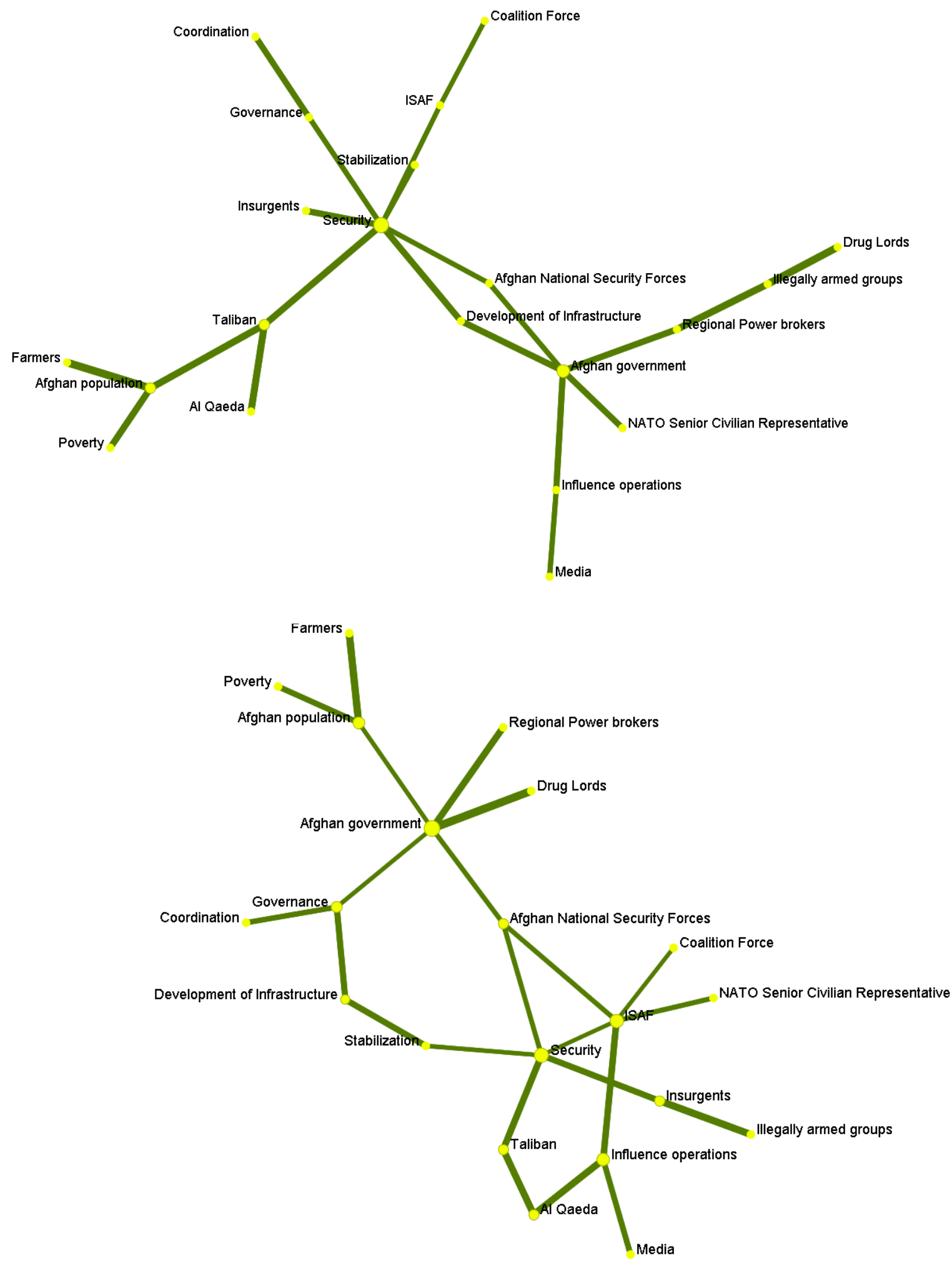

Figure 11. Knowledge structures T1 (top) and T4 (bottom) of the Afghan environment across all participants. 
Table 1. Concept focus on the "Afghan government" concept for the T1, T4, and referent knowledge structures in figures 11 and 6 (referent).

\begin{tabular}{|c|c|c|c|}
\hline Concept & T1 (Figure 11, top) & T4 (Figure 11, bottom) & Referent (Figure 6) \\
\hline \multirow{8}{*}{ Afghan government } & $\begin{array}{l}\text { Development of } \\
\text { infrastructure }\end{array}$ & - & - \\
\hline & $\begin{array}{l}\text { Afghan National Security } \\
\text { Forces }\end{array}$ & $\square$ & 口 \\
\hline & Regional power brokers & $\nabla$ & $\square$ \\
\hline & $\begin{array}{l}\text { NATO senior civilian } \\
\text { representatives }\end{array}$ & - & \multirow{4}{*}{ - } \\
\hline & Influence operations & & \\
\hline & \multirow{3}{*}{ - } & Drug lords & \\
\hline & & Afghan population & \\
\hline & & Governance & $\square$ \\
\hline
\end{tabular}

Note: Check-marked cell represents the inclusion of that concept in defining the "Afghan government" concept.

\subsection{Trust}

As previously mentioned, the primary purpose of the MRMs within COMPOEX is to facilitate the development of explanations and help enhance understanding of the planning environment. This enhanced understanding is the result of being able to explore the operating environment through the MRMs. One factor that may influence participants' degree of understanding is trust in the MRMs. Trust may mediate the extent to which the MRMs can be used to explore, and subsequently, understand the planning environment (figure 12).

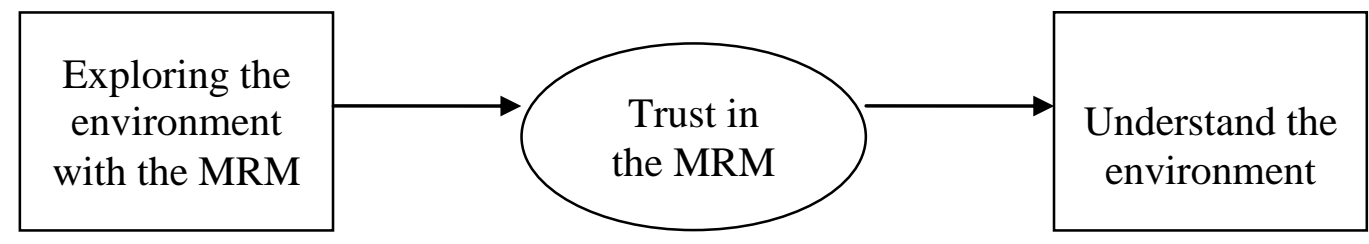

Figure 12. Theoretical relationships of trust as a mediating variable between MRM use and increased understanding of the environment.

Individuals with greater trust in the MRMs may gain a better understanding of the planning environment because they believe that the MRMs generate valid and reliable outcomes. As such, they are able to form an understanding of the interconnections between the elements in the planning environment. Individuals who distrust the MRMs may not see these interconnections because they feel the MRMs do not accurately represent the planning environment.

Trust is also an important component in the successful use of the MRMs. If trust is not calibrated to the true capability of the MRMs, operators may either overrely (misuse) or reject (disuse) the MRMs' capabilities (Lee and See, 2004). These usage strategies may subsequently affect 
understanding. Thus, measuring trust may allow us to better understand how participants are using the MRMs and discern whether trust is a mediating factor that allows participants to understand the planning environment. The following section describes the data collection methods and results surrounding trust in the MRMs.

Participants completed a 13-item human-machine trust measure to report the level of trust they maintained in the MRMs during the exercise (appendix B). This was a modified version of the Jian et al. (2000) original human-machine trust scale. Each item consisted of a seven-point agreement scale. Five of the items were negatively framed and intended to measure distrust of automation. For instance, one of these items asked participants to rate the level of agreement with the following statement: "I am suspicious of the MRMs, action, or output." A high rating on this question indicated a high level of distrust. The remaining eight items were positively framed and were intended to measure trust. A high rating on these questions indicated that the participants had a high level of trust in the MRMs. Ratings for the negatively worded items were reversed scored prior to calculating total trust scores. The total trust score was calculated by averaging participants' ratings among the 13 questions. High values indicate high trust in the MRMs.

Overall, the results show that participants maintained moderate amounts of trust in the MRMs. Trust ratings clustered around the midpoint of the scale, thus indicating that participants did not overtrust or distrust the MRMs. Further analyses revealed that, on average, senior mentors exhibited greater trust in the MRMs than planners (figure 13).

\section{Trust in the MRMs}

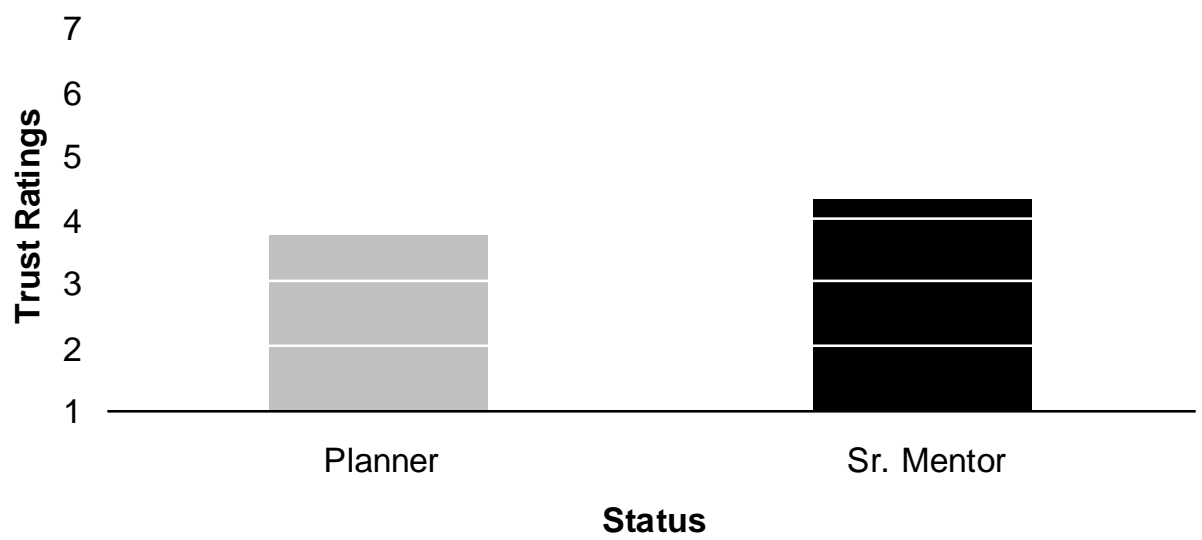

Figure 13. Trust in the MRMs as a function of participant status. 
Results also indicated that trust varied over time as a function of participant status. As shown in figure 14, senior mentors' trust in the MRMs increased slightly over time, while planners' trust demonstrated an opposite trend.

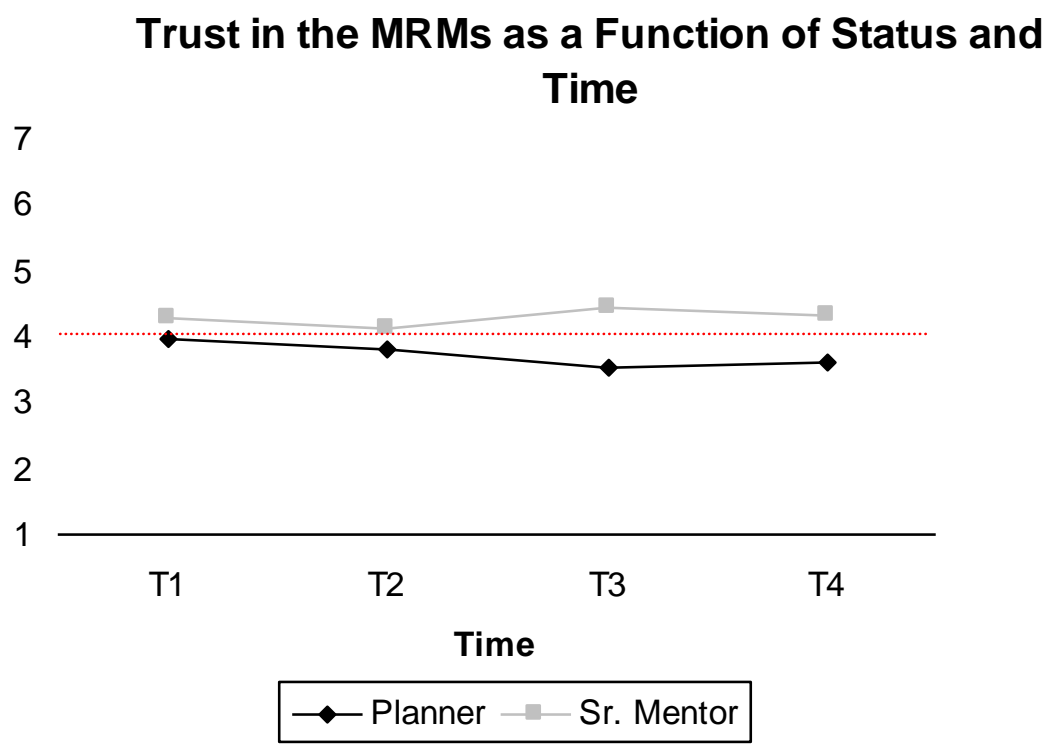

Figure 14. Trust in the MRMs as a function of status and time.

\subsubsection{Predictive Value}

Next, the predictive value of the MRMs was examined to determine if participants believed that the MRMs could be used to project future outcomes in the planning environment. Predictive value was examined using a single-item indicator (Question: I believe that the MRMs have predictive value). This indicator ranged from 1 to 7 . Low values indicated that the MRMs did not have predictive value, whereas high values indicated that the MRMs did have predictive value. Figure 15 shows how predictive value varied over time as a function of planning experience. Note, however, that civilian and military planners' perceptions of predictability converged at the final measurement point. Although the military and civilian participants were not significantly different overall, they took different routes over the event regarding their perception of the MRMs predictive value and ended at the same level at the end of the event. 


\section{Predictive Value as a Function of Planning Experience and Time}

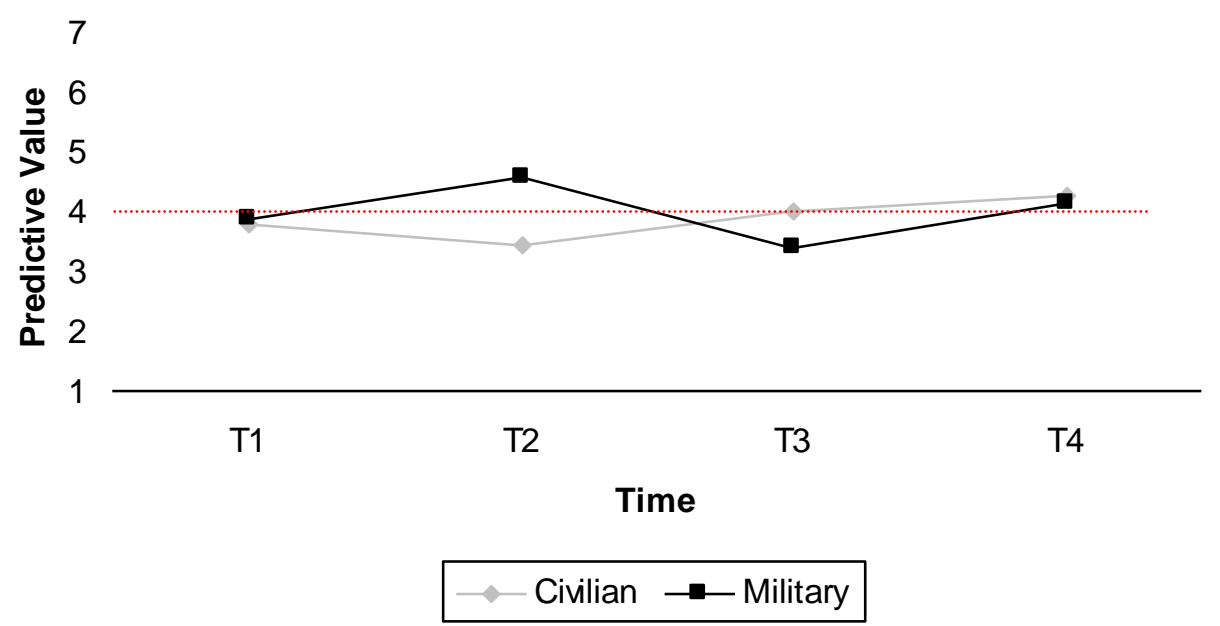

Figure 15. Predictive value as a function of planning experience and time.

\subsubsection{Explorative Value}

Next, the MRMs were examined to determine if they allowed participants to adequately explore the planning environment (Question: I believe that the MRMs enable exploration of the environment.). Explorability was also measured using a seven-point agreement scale. Here, high values indicated that the MRMS allowed for adequate exploration of the planning environment. We hypothesized that there would be a positive relationship between perceived explorability and trust. However, the data failed to support this hypothesis. Though there was a positive correlation between trust and explorability, it failed to reach significance. Additional analyses revealed that, on average, senior mentors had higher explorability ratings than planners (figure 16). 


\section{Explorative Value Across Status}

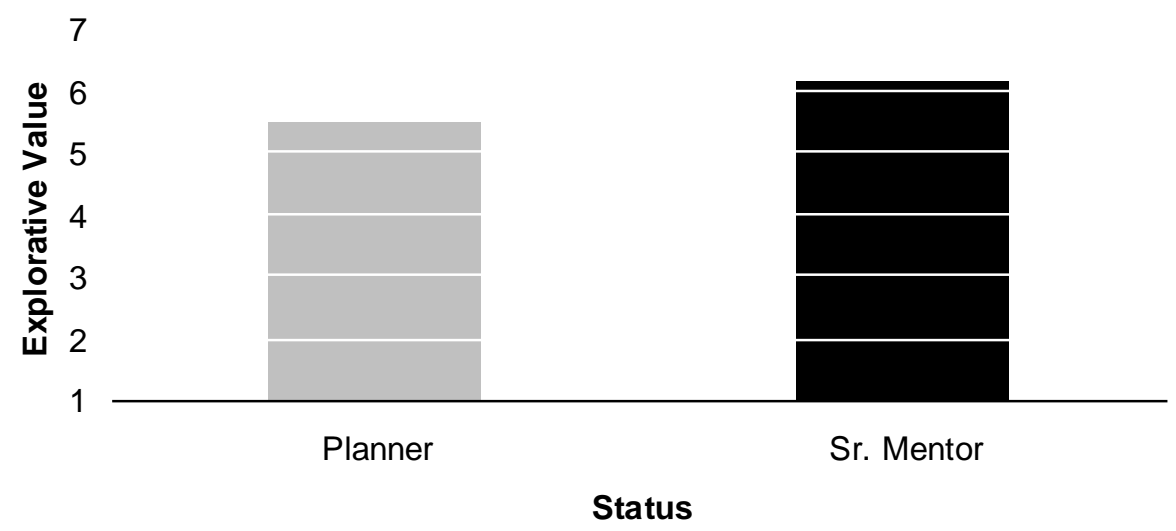

Figure 16. Explorative value across participant status.

\subsubsection{Predictive Value Versus Explorative Value and Usage}

The primary purpose of the MRMs within COMPOEX is to facilitate the development of explanations and help enhance understanding of the operational environment. In practice, however, these principles do not always hold true. Thus, one of the primary questions regarding COMPOEX LOE 2-3 was whether participants would use the MRMs for exploratory or predictive purposes. To answer this question, several analyses were computed. First, the perceptions of predictive value to perceptions of explorative value were examined. As shown in figure 17, participants believed that the MRMs had more explorative than predictive value $(t=-11.9, p<.01)$. Even though the explanatory score is much higher than the prediction score, the prediction score is right at the neutral score of 4 and is not significantly lower. This suggests that participants are still using the MRMs for prediction purposes but not to the degree they are using them for exploration. 


\section{Explorative vs. Predictive Value}

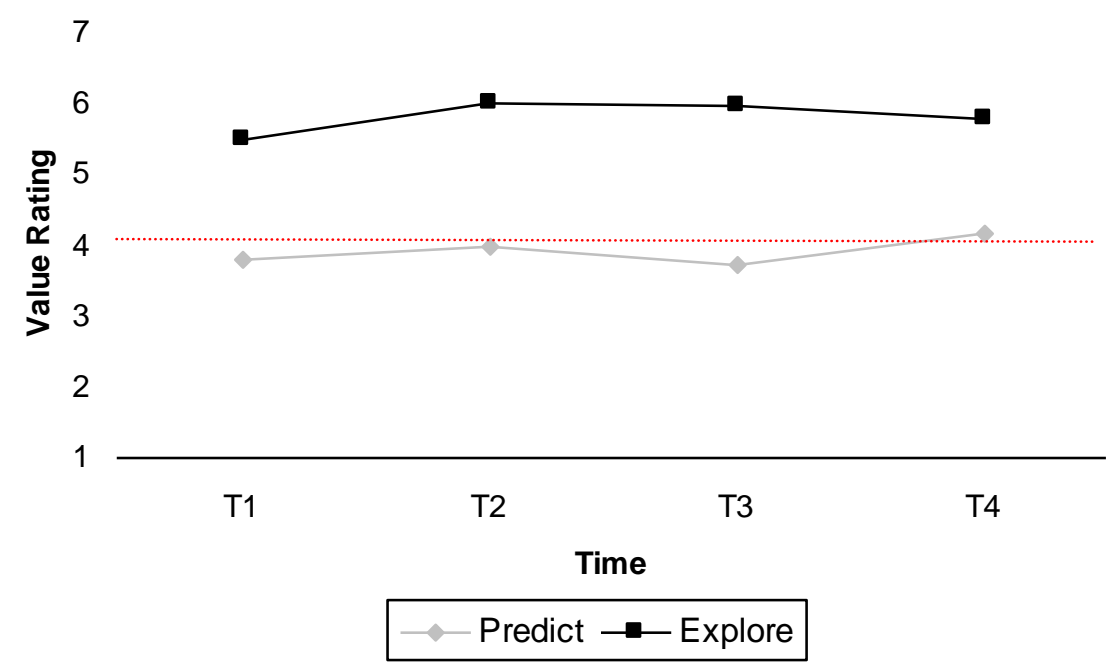

Figure 17. Comparison of explorative value vs. predictive value.

Next, we assessed participant's model usage strategy. This construct was measured using a single item indicator that ranged from 1 to 7 . High scores indicated that the MRMs were used for explaining the environment, whereas low scores indicated that they were used for predictive purposes. Ideally, participants should have used the MRMs to explain the planning environment, rather than to predict future states of the environment. As shown in figure 18, this was indeed true.

Further analyses failed to show significant differences in model usage between planning types (military versus civilian) or levels of expertise (senior mentor versus planner). This lack of significance is welcomed and suggests that participants, regardless of status and experience, used the MRMs to develop explanations rather than for prediction. 


\section{Model Usage Across Time}

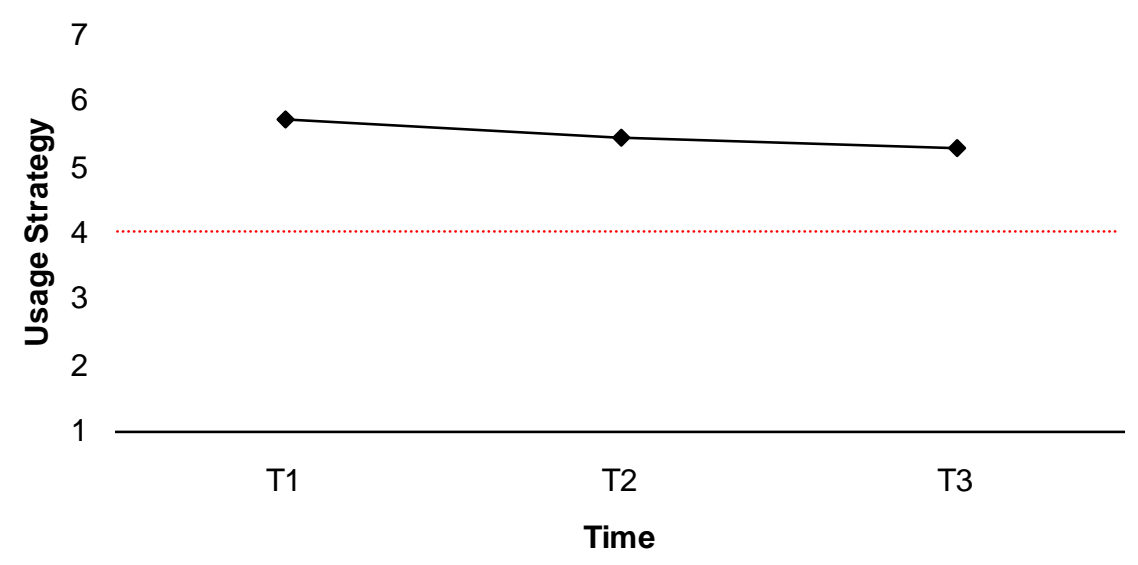

Figure 18. Model usage across time.

\subsubsection{Workload}

An examination of the workload across several dimensions was conducted to investigate the effect COMPOEX had on workload and to monitor workload across the duration of the event. The National Aeronautics and Space Administration (NASA) Task Load Index (TLX) (Hart and Staveland, 1988) workload measure was used and administered three times beginning on the Friday of the training week and twice in the execution week (Wednesday and Friday). The NASA-TLX is a subjective workload assessment measure that allows users to perform subjective workload assessments on operator(s) working with various human-machine systems. A multidimensional rating procedure, NASA-TLX derives an overall workload score based on a weighted average of ratings on six subscales. It can be completed in a short amount of time through a simple computer program.

- "Mental demand" refers to how much mental and perceptual activity was required (thinking, deciding, calculating, remembering, looking, searching, etc.) during the task. The respondent should consider whether the task was easy or demanding, simple or complex, and exacting or forgiving.

- "Physical demand" measures the required physical activity in relation to whether the task was easy or demanding, slow or brisk, slack or strenuous, and restful or laborious.

- The amount of experienced time pressure is measured by the "temporal demand" subscale. It addresses issues such as whether the pace of interaction was slow and leisurely or rapid and frantic.

- "Performance" refers to how successful respondents think they were in accomplishing the goals of the task set by the experimenter, and how satisfied they were with their performance in accomplishing these goals. 
- The criteria of "effort" requests the respondents to assess how hard they had to work (mentally and physically) to accomplish the level of performance they achieved.

- The "frustration" level measures how insecure, discouraged, irritated, stressed and annoyed versus secure, confident, relaxed, and complacent subjects felt during the task.

The levels of total workload showed a gradual increase over the duration of the event along with most of the other dimensions of workload (figure 19). These results are primarily attributed to the increased tempo of the event as the planning teams neared their product deadlines at the end of the event. Among the two dimensions showing slight but nonsignificant trends in the opposite direction (decreasing over time) are the physical demand and frustration dimensions. Although subtle and nonsignificant, it is informative that frustration appears to decrease even though other types of workload appear to be on the increase. This suggests that some degree of learning and familiarity were gained with the use of the COMPOEX tool over the duration of the event even though overall workload was increasing at the same time.

\section{Workload Dimensions over Time}

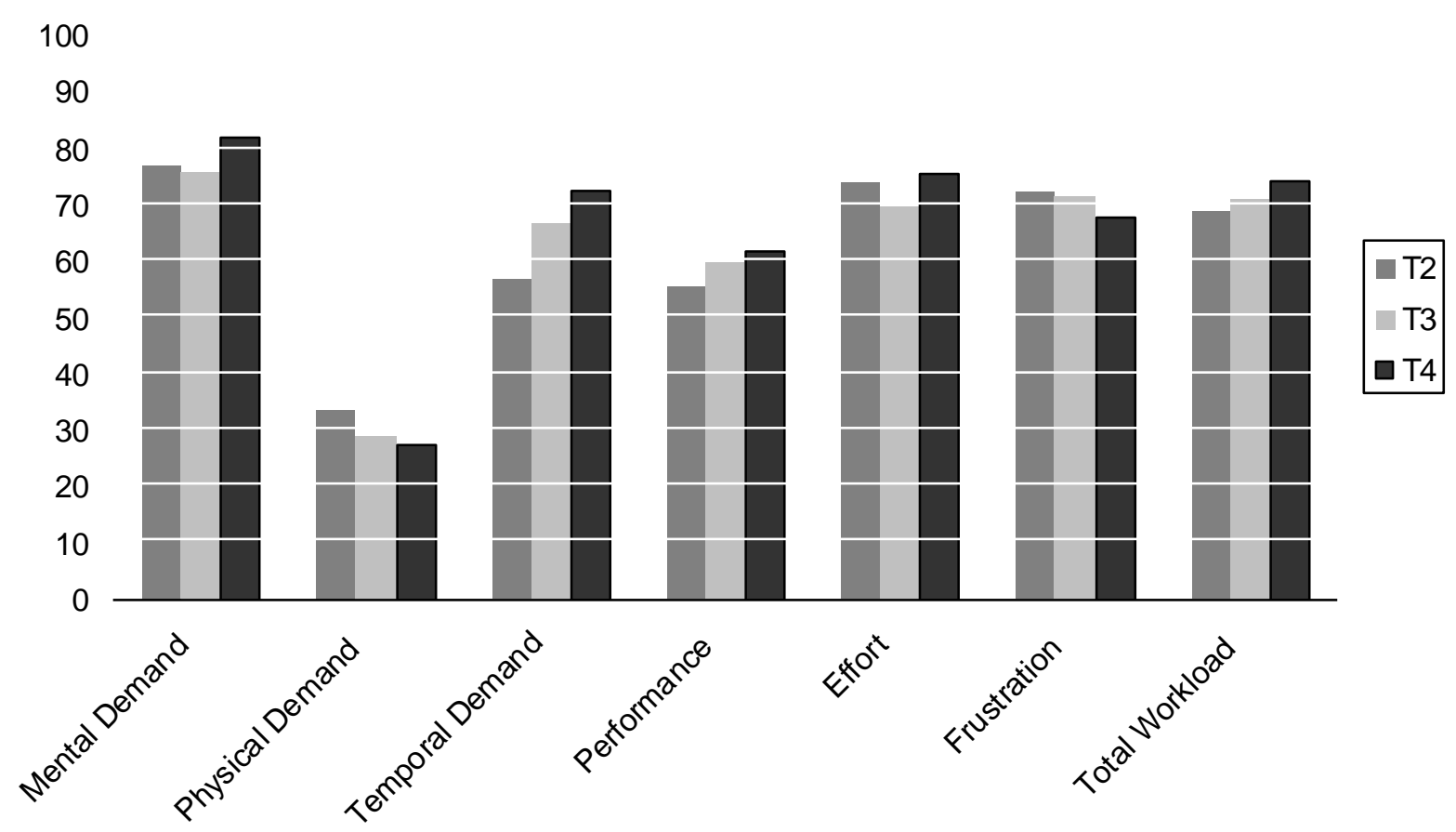

Figure 19. Workload results by dimension over time.

Again, these results are only suggestive due to full experimental controls not being in place. Any differences among the workload dimensions were examined for each administration between military and civilian personnel. There were only two significant differences between those two groups. The first was a marginal difference during the middle of the execution week (T3) for the 
frustration dimension. Frustration levels for the military experienced participants were marginally higher than those of the civilian/government experienced participants $(t=1.94$, $p<.07$ ) during the middle of the execution week (Wednesday). The other significant difference was evident on the last day of the execution week, when the military participants reported a significantly higher temporal demand than the civilian participants $(t=3.17, p<.01)$.

\subsection{User and Expert Feedback}

The past three results sections investigated the planning products produced in the event, how those products were produced through different patterns of interactions with others and COMPOEX, and the effect those interactions had on key human performance factors. The final result section will examine feedback from the participants on COMPOEX and conclude with the results from the expert evaluators that observed the entire event.

\subsubsection{User Feedback}

On the last day of the execution week, participants were asked 15 questions (appendix C) related to the capabilities and potential benefits of using COMPOEX. Each question was answered on a five-point Likert scale in which a favorable response is scored higher (e.g., 5) and an unfavorable response is scored lower (e.g., 1) (figure 20). Four items were significantly higher than a neutral (3) score, Q2 $(t=2.85, p<.05), \mathrm{Q} 3(t=8.52, p<.05), \mathrm{Q} 4(t=4.0, p<.05)$, and Q5 $(t=2.3$, $p<.05)$ (table 2). These represent capabilities that the participants felt that the COMPOEX system excelled at during this event. On the other hand, there were two items that were significantly lower than a neutral (3) score, Q9 $(t=-3.58, p<.05)$ and Q15 $(t=-3.3, p<.05)$ (table 2). These represent capabilities that the participants felt that COMPOEX did not fully support. Note the similarity of questions 14 and 15, which ask about the appropriateness level of the MRMs for operational planning (Q14) and strategic planning (Q15). The score for operational planning was not significantly below neutral but was lower for strategic planning, suggesting that the level the MRMs represented for this event were more conducive to operational versus strategic planning. 


\section{Participant Feedback on COMPOEX Capabilities}

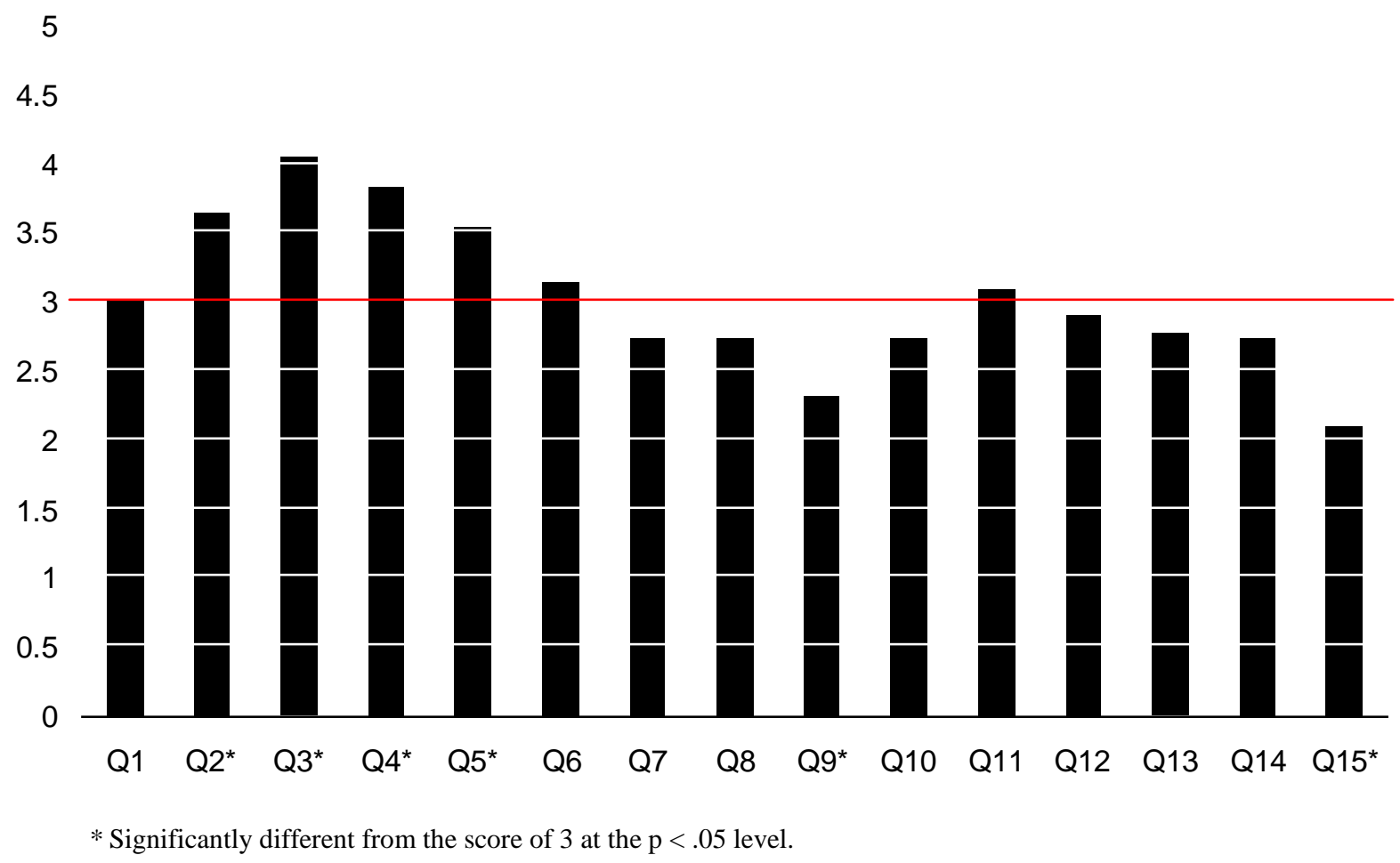

Figure 20. Average scores for each COMPOEX capability item answered by the participants.

Table 2. Items that were significantly higher and lower than the neutral score of 3 among participants.

\begin{tabular}{|l|l|}
\hline \multicolumn{1}{|c|}{ High-Scoring Items } & \multicolumn{1}{c|}{ Low-Scoring Items } \\
\hline $\begin{array}{l}\text { Q2. COMPOEX allowed the exploration of individual } \\
\text { actions alone from each elements of power. }\end{array}$ & $\begin{array}{l}\text { Q9. The plan contains more than one branch to account } \\
\text { for multiple theories and ambiguity in some data. }\end{array}$ \\
\hline $\begin{array}{l}\text { Q3. COMPOEX allowed the exploration of multiple } \\
\text { actions together from a single element of power. }\end{array}$ & $\begin{array}{l}\text { Q15. The MRMs are at an appropriate level to support } \\
\text { strategic level planning. }\end{array}$ \\
\hline $\begin{array}{l}\text { Q4. COMPOEX allowed the exploration of combined } \\
\text { actions from different elements of power. }\end{array}$ & \\
\hline $\begin{array}{l}\text { Q5. COMPOEX allowed the exploration of modified } \\
\text { strengths and sequence of actions from multiple } \\
\text { elements of power. }\end{array}$ & \\
\hline
\end{tabular}

There were several differences evident among these items between military and civilian participants. Among the 15 questions, the military participants scored significantly higher on four of the questions (table 3): Q1 $(t=1.73, p<.05)$, Q8 $(t=1.73, p<.05)$, Q9 $(t=1.74$, $p<.05)$, and Q15 $(t=2.4, p<.05)$. The civilian participants did not score significantly higher than the military participants on any of the items. Two of these items are the same as the low-scoring items reported in table 2. If the civilian scores are removed from those two items, there would be no items that are significantly lower than a neutral score. Therefore, the 
civilian/government-experienced participants felt that COMPOEX did not fully support the capabilities mentioned in Q9 and Q15, whereas the military-experienced participants felt that all items were supported or well supported by COMPOEX.

Table 3. Items that were significantly higher among military-experienced participants vs. civilian/governmentexperienced participants.

Q1. COMPOEX allowed the exploration of actions from the full range of DIME elements of power in obtaining priority effects.

Q8. Players using COMPOEX created the most likely plan to achieve the priority effects based on COMPOEX derived ToCs.

Q9. The plan contains more than one branch to account for multiple theories and ambiguity in some data. Q15. The MRMs are at an appropriate level to support strategic level planning.

\subsubsection{User Satisfaction}

User satisfaction with three specific tools within the COMPOEX system was measured using the System Usability Scale (SUS) (Brooke, 1996). The SUS is a simple 10-item scale that addresses subjective assessments of usability at a general and global level (appendix D). The 10-item scale is meant to be used as a single score and not broken into individual item scores. The three tools that were assessed were the primary tools used in LOE 2-3-Sandbox, CPT, and OET - with its multiple views. The OET had the highest usability score, 60 out of 100, while Sandbox and CPT both had scores of 54. All the user satisfaction scores hovered around the 50\%-60\% range, which suggests that the users did not find the COMPOEX interfaces unusable, did not find them incredibly user friendly, and were fairly neutral toward the COMPOEX tool interfaces. This suggests that the current tool interfaces are functional but have room for improvement, which may further improve performance parameters such as ease of learning, user satisfaction, frustration, trust, and understanding.

Further analyses shows that there was a significant user satisfaction difference between civilian and military experienced participants for the CPT $(t=-2.0, p=.05)$ but not for the Sandbox or the OET (figure 21). These results indicate that the participants were most pleased with the interface of the OET, and that the CPT interface created different user experiences between military and civilian experienced participants, with it working better for those with a military background. 


\section{COMPOEX User Satisfaction}

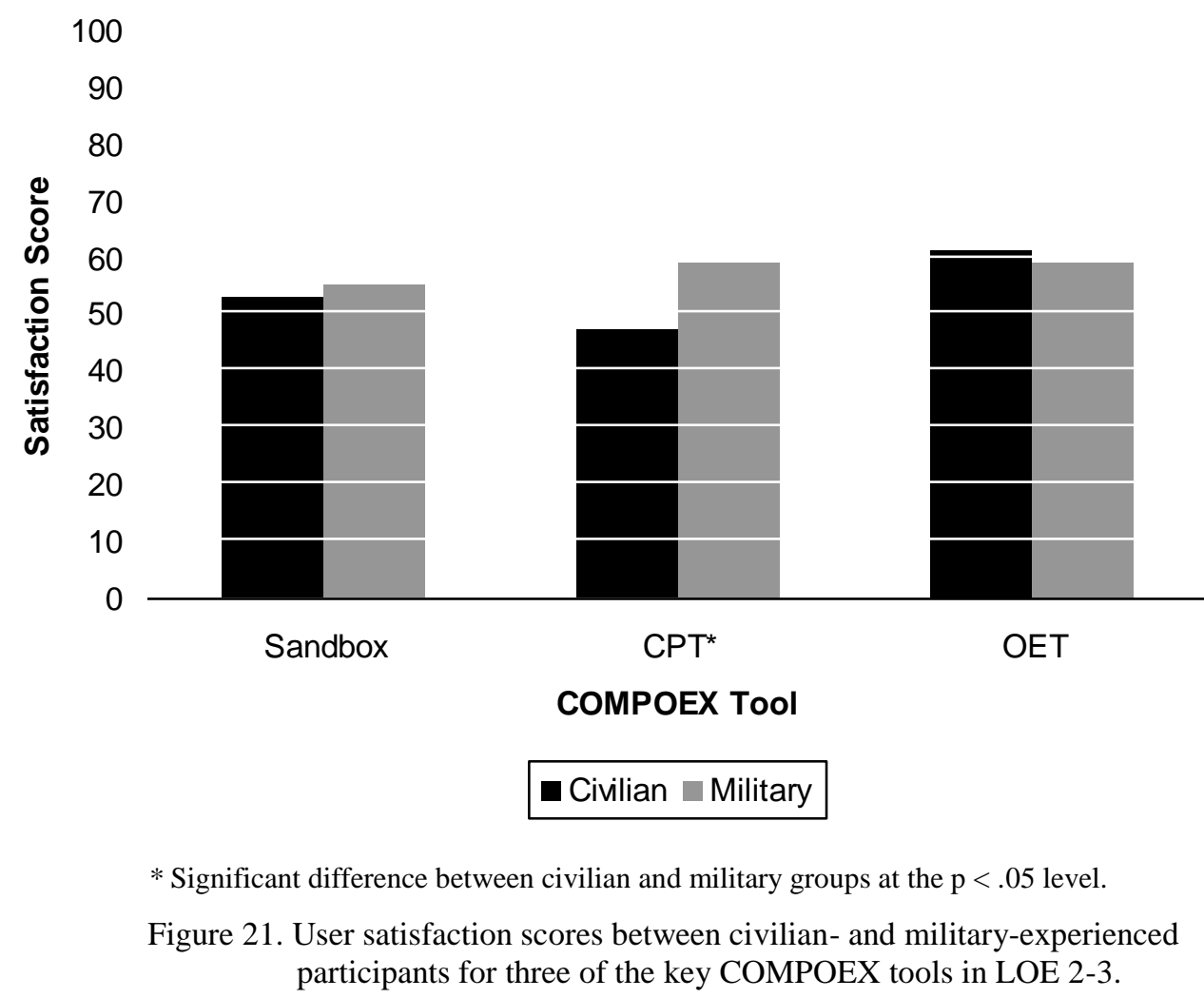

\subsubsection{Expert Evaluations}

Three expert evaluators with extensive experience in planning and operational support observed both the training and execution week. Before the execution week, the expert evaluators completed the same set of questions that the participants completed in appendix $\mathrm{C}$ on COMPOEX capabilities though modified to address traditional planning capabilities (appendix E). On the last day of the execution week and after observing the participants using COMPOEX for the duration of the event, the expert evaluators completed the COMPOEX capabilities questions (appendix C). To assess any differences between traditional and COMPOEX-assisted planning, analysis of the results of these two evaluations were completed. COMPOEX was evaluated to perform items Q1, Q4, Q5, and Q7 significantly better than traditional planning methods and tools (figure 22). Table 4 provides the content of the items. No traditional planning capabilities were evaluated significantly higher than COMPOEX planning capabilities. The basic trend for 11 of the 13 comparative items was in the direction favoring COMPOEX. 


\section{Expert Evaluation Ratings between \\ Traditional \& COMPOEX Planning}

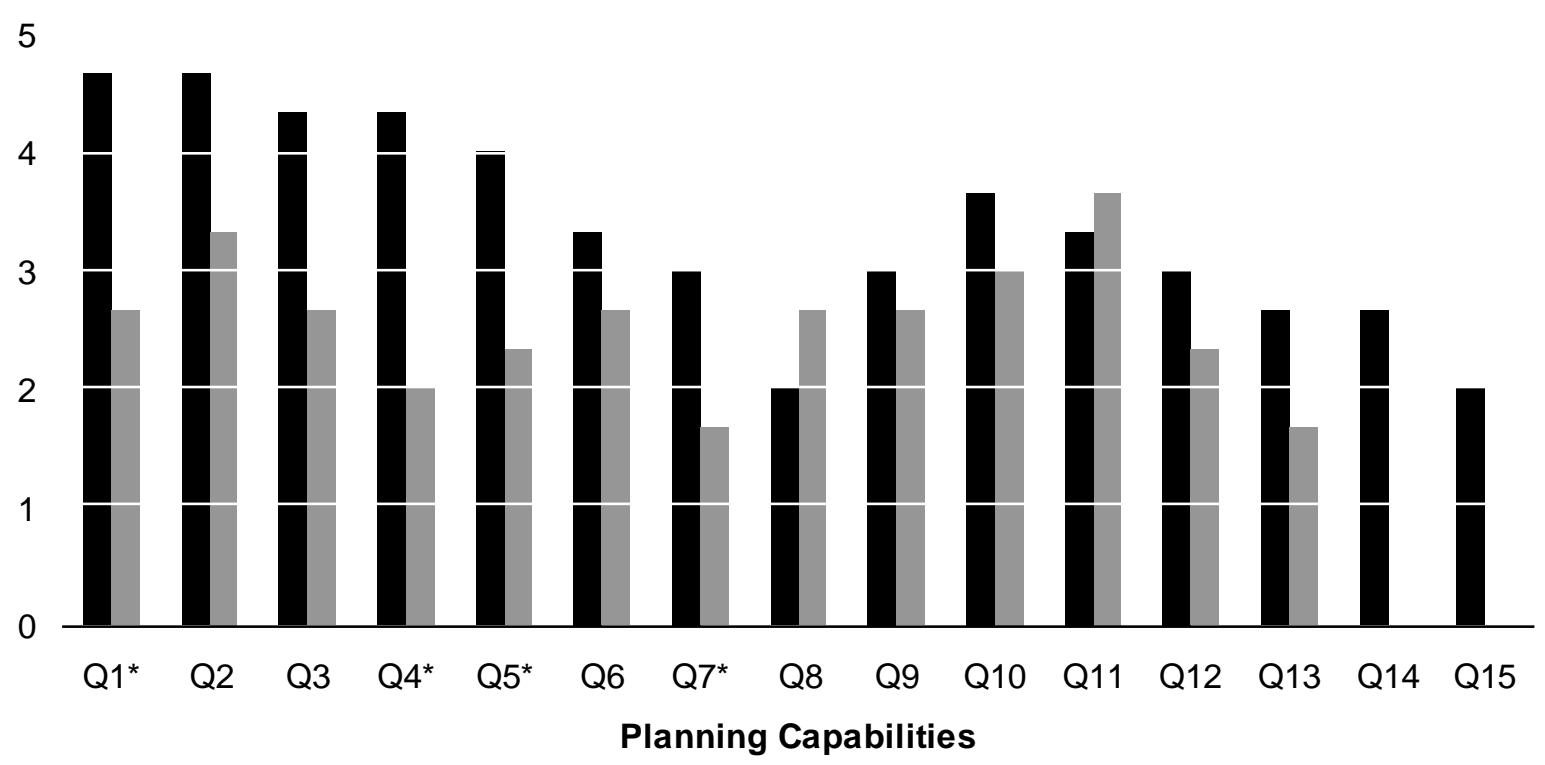

- COMPOEX Plan $\square$ Traditional Plan

* Significant difference between COMPOEX and traditional planning at the $\mathrm{p}<.05$ level.

Figure 22. Expert evaluations between COMPOEX and traditional planning capabilities.

Table 4. Capabilities that were evaluated significantly higher for COMPOEX-assisted planning compared with traditional planning.

Q1. COMPOEX allowed the exploration of actions from the full range of DIME elements of power in obtaining priority effects.

Q4. COMPOEX allowed the exploration of combined actions from different elements of power.

Q5. COMPOEX allowed the exploration of modified strengths and sequence of actions from multiple elements of power.

Q7. COMPOEX allowed the development of a comprehensive, achievable whole of the government plan with multiple lines of effort and sublines of effort.

Comparing these results with the results from the participants shows agreement on items Q4 and Q5, which focus on the exploration of combined actions, strengths, and sequencing of actions from multiple elements of power. The other two capability items at which the participants thought COMPOEX excelled were Q2 and Q3 (table 2). The expert evaluators appear to agree by evaluating COMPOEX considerably higher than traditional planning on these but did not reach statistical significance, primarily due to the small sample size of only three expert evaluator ratings for this analysis. The expert evaluators also agreed with the participants on the appropriateness of the MRMs at the operational planning level (figure 22, Q14) but less so at the strategic planning level (figure 22, Q15). 


\section{Conclusions}

The COMPOEX system was evaluated in LOE 2-3 on what products it facilitated, how it facilitated those products, the effect it had on understanding, and the results of its use in this 2-week planning event. The analyses across each of these areas showed that COMPOEX consistently had positive results and appears to support the planning process in the areas mentioned. These results are only suggestive because full experimental controls were not in place.

The output and products that COMPOEX facilitated were evaluated in terms of the time and effort to develop the MRMs and the planning outputs produced. The time and resources required for the development of the MRMs compared favorably with the requirements for nodal network development. Hundreds of actions were examined in less than 10 days of planning, and 10 effects were integrated into a single plan. During this process, a fourth line of effort was identified as critical to the operation and included in the final integrated plan.

The coordination that was facilitated by COMPOEX showed that it did not restrict collaboration across the planners, whether it was across lines of effort, between leadership and planners, or between military and civilian/government participants. Patterns of coordination among the participants with COMPOEX also showed that reliance on tool support personnel declined over time, suggesting that participants were able to learn and increase their proficiency with the COMPOEX tools.

Interactions with COMPOEX produced several positive effects among the participants that support the planning process. Improved understanding across both civilian and military participants as well as across experience levels was evident over time. Trust in the MRMs was at moderate levels, and no difference in trust was evident between military and civilian participants. As intended, participants placed greater emphasis on the explorative use of the MRMs over using them for prediction purposes.

The use of COMPOEX to support and facilitate planning resulted in several perceived benefits and strengths by the participants and the SMEs. The participants evaluated four capabilities at which COMPOEX significantly excelled and two at which it showed weaknesses. Along with these capabilities, moderate levels of user satisfaction were reported with the user interface of the COMPOEX tools, including a significant difference among civilian and military participants for the CPT. Finally, the SMEs rated COMPOEX significantly better on four capabilities than traditional planning tools and procedures. 


\section{References}

COMPOEX (Conflict Modeling, Planning, and Outcome Experimentation): Phase 2A Final Report; TR-COMPOEX-300; BAE Systems: Arlington, VA, May 2007.

Brooke, J. SUS: A “Quick and Dirty” Usability Scale. In Usability Evaluation in Industry; Jordan, P. W.; Thomas, B.; Weerdmeester, B. A.; McClelland, A. L., Eds.; Taylor and Francis: London, 1996.

Cooke, N. M.; Schvaneveldt, R.W. Effects of Computer Programming Experience on Network

Representations of Abstract Programming Concepts. International Journal of Man-Machine Studies 1988, 29, 407-427.

Dayton, T.; Durso, F. T.; Shepard, J. D. A Measure of Knowledge Reorganization Underlying Insight. In Pathfinder Associative Networks: Studies in Knowledge Organization;

Schvaneveldt, R., Ed.; Ablex: Norwood, NJ, 1990; pp 121-133.

Durso, F. T.; Coggins, K. A. Graphs in the Social and Psychological Sciences: Empirical Contributions of Pathfinder. In Pathfinder Associative Networks: Studies in Knowledge Organization; Schvaneveldt, R., Ed.; Ablex: Norwood, NJ, 1990; pp 121-133.

Gilbert, N.; Troitzsch, K. G. Simulation for the Social Scientist; Open University Press: Buckingham, UK, 2005.

Goldsmith, T. E.; Johnson, P.J. A Structural Assessment of Classroom Learning. In Pathfinder Associative Networks: Studies in Knowledge Organization; Schvaneveldt, R., Ed.; Ablex: Norwood, NJ, 1990; pp 121-133.

Hart, S. G.; Staveland, L. E. Development of NASA-TLX (Task Load Index): Results of Empirical and Theoretical Research. In Human Mental Workload; Hancock, P. A.; Meshkati, N., Eds.; North-Holland: Amsterdam, 1988; pp 139-183.

Jian, J.; Bisantz, A. M.; Drury, C. G. Foundations for an Empirically Determined Scale of Trust in Automated Systems. International Journal of Cognitive Ergonomics 2000, 4, 53-71.

Lee, J. D.; See, K. A. Trust in Automation: Designing for Appropriate Reliance. Human Factors 2004, 46, 50-80.

Norman, D.A. The Design of Everyday Things; Doubleday: New York, 1988.

Rubin, D. C. Directed Graphs as Memory Representations: The Case of Rhyme. In Pathfinder Associative Networks: Studies in Knowledge Organization; Schvaneveldt, R., Ed.; Ablex: Norwood, NJ, 1990; pp 121-133. 
Schvaneveldt, R. W. Ed. Pathfinder Associative Networks: Studies in Knowledge Organization; Ablex: Norwood, NJ, 1990.

Schvaneveldt, R.W.; Durso, F. T.; Goldsmith, T. E.; Breen, T. J.; Cooke, N. M.; Tucker, R. G.; DeMaio, J. C. Measuring the Structure of Expertise. International Journal of Man-Machine Studies 1985, 23, 699-728.

Scott, J. Social Network Analysis: A Handbook; Sage Publications, Ltd.: London, 2000.

Siegler, R. S. Children's Learning. American Psychologist 2005, 60, 769-778. 
INTENTIONALLY LEFT BLANK. 


\section{Appendix A. COMPOEX Program Components}

This appendix appears in its original form, without editorial change. 


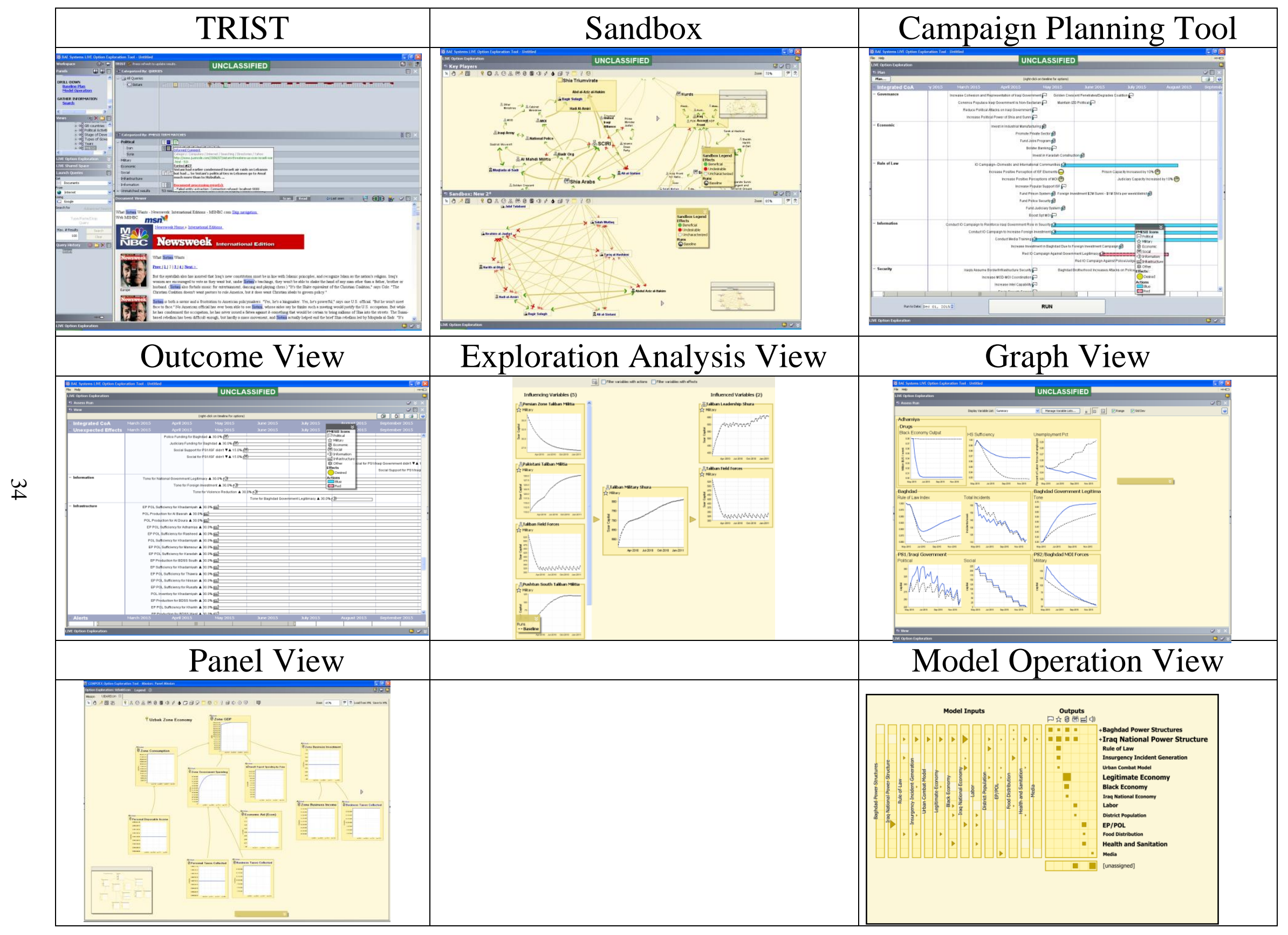




\section{Appendix B. Trust Questionnaire}

This appendix appears in its original form, without editorial change. 


\section{Trust Questionnaire}

Below is a list of statements for evaluating your trust in the in the COMPOEX multi-resolution models (MRM). Please rate the statements on the extent to which you believe they describe the MRMs. You may refer to the definitions below to help you with your ratings.

\section{Definitions:}

Misleading - the model leads one to commit errors

Unpredictable - the system's future behavior is unknown

Inconsistent - the model output is erratic

Valid - the correct actions can be inferred from the information presented by the model

Dependable - the system is worthy of user trust

Credible - the system is worthy user confidence

Reliable - the information presented by the system corresponds to reality

Trustworthy - the system's behavior is reliable

1. The MRM is misleading.

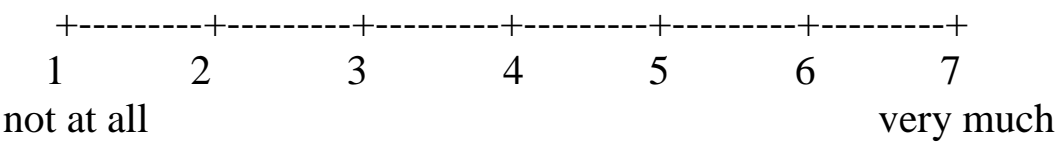

2. The MRM behaves in an unpredictable manner.

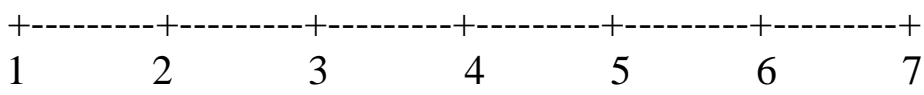

not at all

very much

3. I am suspicious of the MRM's output.

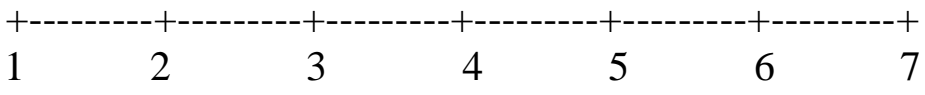

not at all

very much

4. The MRM's output is inconsistent.

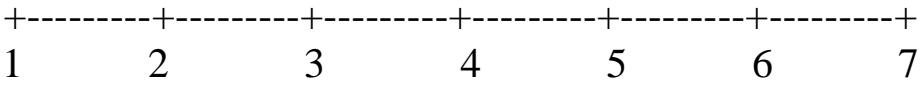

not at all

very much

5. I am wary of the MRM.

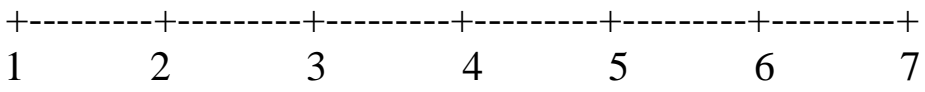

not at all

very much

6. I am confident in the MRM.

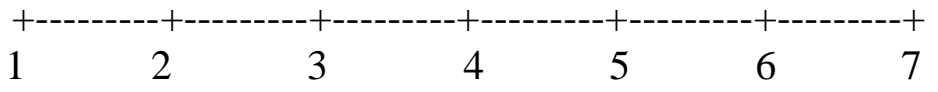

not at all

very much 
7. The MRM provides valid models.

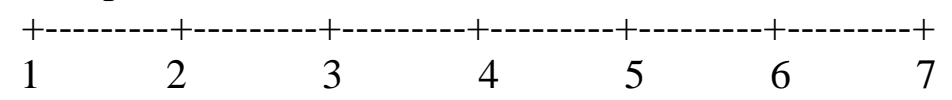

not at all

very much

8. The MRM is dependable.

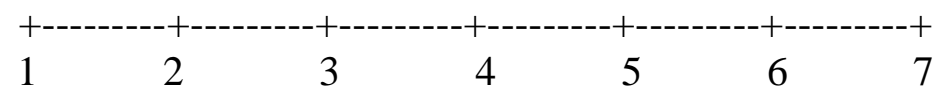

not at all

very much

9. The MRM is reliable.

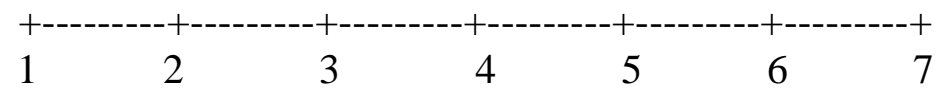

not at all

very much

10. I can trust the MRM.

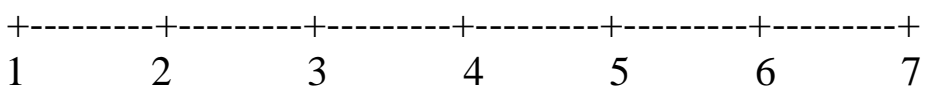

not at all

very much

11. The MRM has credibility.

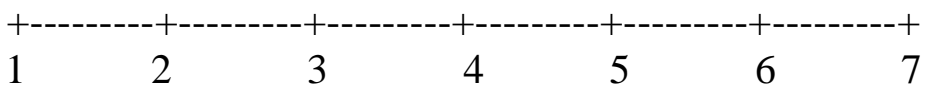

not at all

very much

12. I am familiar with how the MRM generates its models.

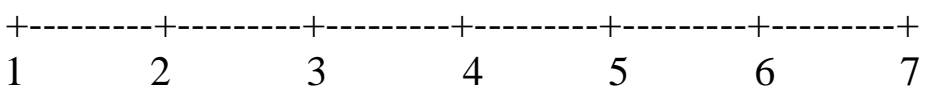

not at all

very much

13. I believe that the MRMs have predictive value.

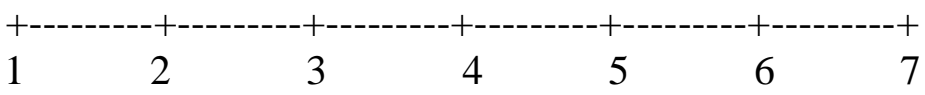

not at all

very much

14. I believe that the MRMs enable exploration of the environment.

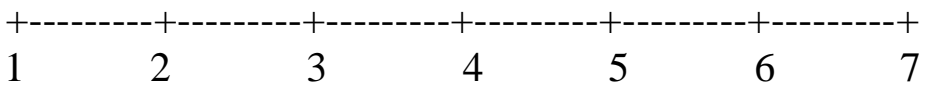

not at all

very much

15. Up to this point in the event, I have used the MRM/s primarily for:

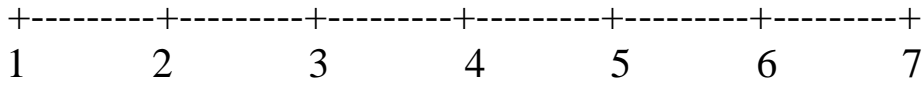

Prediction

Explanation 
INTENTIONALLY LEFT BLANK. 


\section{Appendix C. Conflict Modeling, Planning, and Outcomes Experimentation Program (COMPOEX) Capability Questionnaire}




\section{COMPOEX Capability Questionnaire}

Please provide your rating from the drop-down menu for each item below that best describes your observations up to this point in the event.

1. COMPOEX allowed the exploration of actions from the full range of diplomatic, information, military, and economic elements of power in obtaining priority effects.
1
2
3
4
5

Strongly Disagree

Strongly Agree

2. COMPOEX allowed the exploration of individual actions alone from each elements of power.

1

Strongly Disagree

\section{2}

3

3. COMPOEX allowed the exploration of multiple actions together from a single element of power.
1
2

Strongly Disagree
4

\section{Strongly Agree}

4. COMPOEX allowed the exploration of combined actions from different elements of power.
1
2
3
4
5

Strongly Disagree

Strongly Agree

5. COMPOEX allowed the exploration of modified strengths and sequence of actions from multiple elements of power.

12

Strongly Disagree

3

4

5

Strongly Agree

6. COMPOEX allowed the integration of all priority effects and the use of all elements of power across all domains of the environment.
1
2
3
4
5

Strongly Disagree

Strongly Agree

7. COMPOEX allowed the development of a comprehensive, achievable whole of government plan with multiple lines of effort and sub-lines of effort.
1
2
3
4
5
Strongly Agree

Strongly Disagree

8. Players using COMPOEX created the most likely plan to achieve the priority effects based on COMPOEX derived Theory of Conflict(s).

$\begin{array}{lllcc}1 & 2 & 3 & 4 & 5 \\ \text { y Disagree } & & & & \text { Strongly Agree }\end{array}$

Strongly Disagree

9. The plan contains more than one branch to account for multiple theories and ambiguity in some data.
1
2
3
4
5
Strongly Agree

Strongly Disagree 
1. Detailed metrics for achieving the priority effects were produced.
1
2
3
4
5

Strongly Disagree

Strongly Agree

2. Key assumptions were identified and challenged during the planning process to understand the range of possible outcomes.

$\begin{array}{llllll}1 & 2 & 3 & 4 & 5\end{array}$

Strongly Disagree $\quad$ Strongly Agree

3. COMPOEX allowed the development and modification of feasible Theories of the Conflict.

$\begin{array}{lllcc}1 & 2 & 3 & 4 & 5 \\ \text { Strongly Agree }\end{array}$

4. These Theories of Conflict were well represented in a Multi-resolution model (MRM).
1
2
3
4
5
Strongly Agree

Strongly Disagree

14. The MRMs are at an appropriate level to support operation level planning.

$\begin{array}{ccccc}1 & 2 & 3 & 4 & 5 \\ \text { Strongly Disagree } & & & & \text { Strongly Agree }\end{array}$

15. The MRMs are at an appropriate level to support strategic level planning.

$\begin{array}{lllll}1 & 2 & 3 & 4 & 5\end{array}$

Strongly Disagree $\quad$ Strongly Agree

16. Closing comments on any of the above items and/or your experience with the COMPOEX system during this event: 
INTENTIONALLY LEFT BLANK. 


\section{Appendix D. System Usability Scale}

This appendix appears in its original form, without editorial change. 


\section{System Usability Scale}

1. I think that I would like to use this system frequently

Strongly Strongly

disagree agree

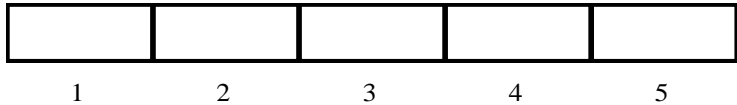

2. I found the system unnecessarily complex

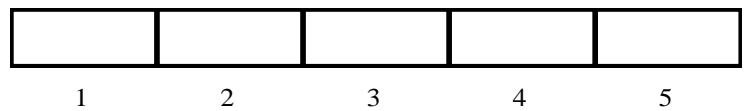

3. I thought the system was easy to use

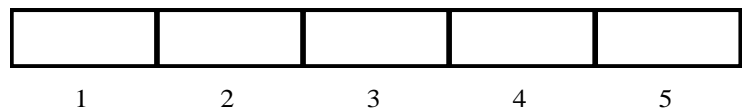

4. I think that I would need the support of a technical person to be able to use this system

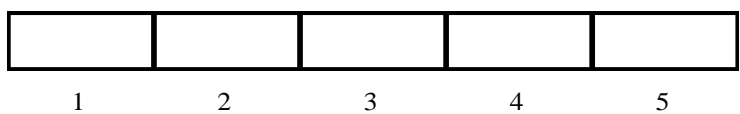

5. I found the various functions in this system were well integrated

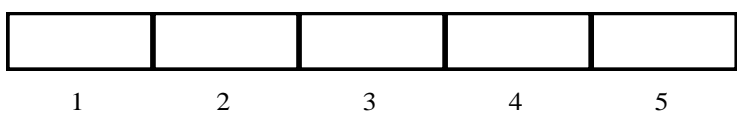

6. I thought there was too much inconsistency in this system

7. I would imagine that most people would learn to use this system very quickly
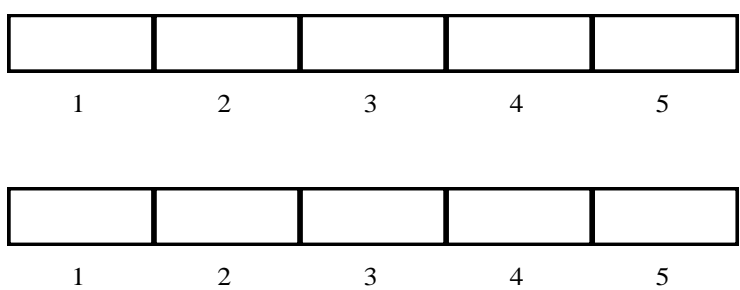

8. I found the system very cumbersome to use

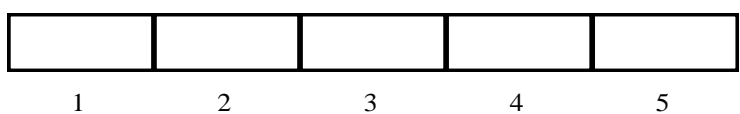

9. I felt very confident using the system

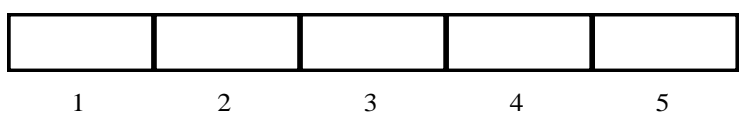

10. I needed to learn a lot of things before I could get going with this system

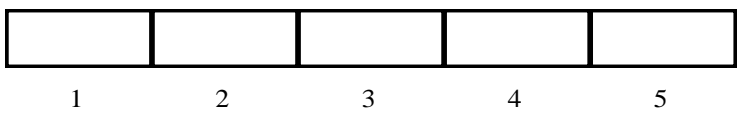




\section{Appendix E. Traditional Planning Capability Baseline Questionnaire}

This appendix appears in its original form, without editorial change. 


\section{Traditional Planning Capability Baseline Questionnaire}

Please provide your rating from the drop-down menu for each item below that best describes your observations of traditional planning tools and processes.

1. Traditional planning allows the exploration of actions from the full range of diplomatic, information, military, and economic elements of power in obtaining priority effects.

$\begin{array}{ccccc}1 & 2 & 3 & 4 & 5 \\ \text { Strongly Disagree } & & & & \text { Strongly Agree }\end{array}$

2. Traditional planning allows the exploration of individual actions alone from each elements of power.

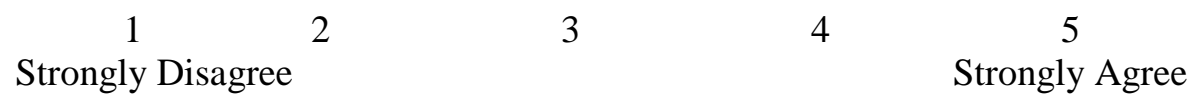

3. Traditional planning allows the exploration of multiple actions together from a single element of power.

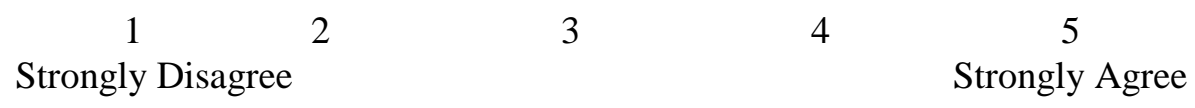

4. Traditional planning allows the exploration of combined actions from different elements of power.
2
3
4
5
Strongly Disagree
Strongly Agree

5. Traditional planning allows the exploration of modified strengths and sequence of actions from multiple elements of power.
12
3
4
5
Strongly Disagree
Strongly Agree

6. Traditional planning allows the integration of all priority effects and the use of all elements of power across all domains of the environment.
12
34
45
Strongly Agree

Strongly Disagree

7. Traditional planning allows the development of a comprehensive, achievable whole of government plan with multiple lines of effort and sub-lines of effort.

$\begin{array}{ccccc}1 & 2 & 3 & 4 & 5 \\ \text { Strongly Disagree } & & & \text { Strongly Agree }\end{array}$

8. Players using traditional planning tools and processes create the most likely plan to achieve the priority effects based on COMPOEX derived Theory of Conflict(s).
Strongly Disagree
3
4
5
Strongly Agree

9. Plans created by traditional planning tools \& processes contain more than one branch to account for multiple theories and ambiguity in some data.
1
2
3
4
5
Strongly Disagree
Strongly Agree 
10. Detailed metrics for achieving the priority effects are produced using traditional planning tools and processes.

$\begin{array}{ccccc}1 & 2 & 3 & 4 & 5 \\ \text { Strongly Disagree } & & & & \text { Strongly Agree }\end{array}$

11. Key assumptions are identified and challenged during the traditional planning process to understand the range of possible outcomes.

$\begin{array}{ccccc}1 & 2 & 3 & 4 & 5 \\ \text { Strongly Disagree } & & & & \text { Strongly Agree }\end{array}$

12. Traditional planning allows the development and modification of feasible Theories of the Conflict.

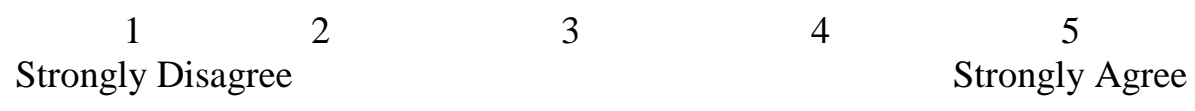

13. These Theories of Conflict are well represented in traditional plans.

$\begin{array}{ccccc}1 & 2 & 3 & 4 & 5 \\ \text { Strongly Disagree } & & & \text { Strongly Agree }\end{array}$




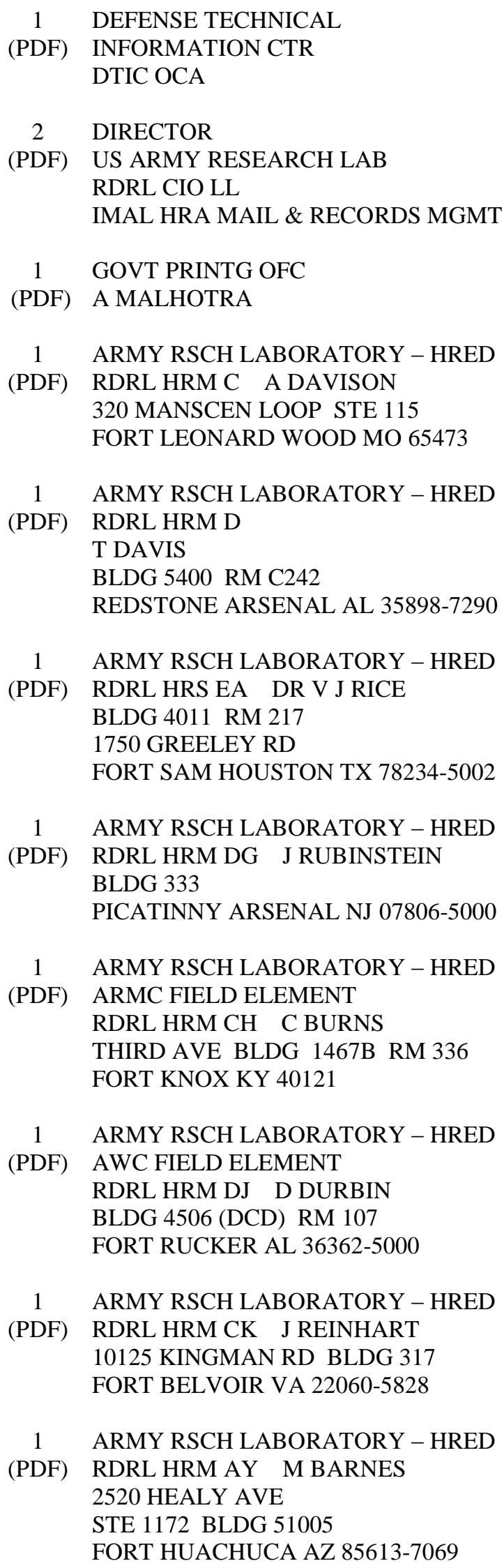

1 ARMY RSCH LABORATORY - HRED

(PDF) RDRL HRM AP D UNGVARSKY

POPE HALL BLDG 470

BCBL 806 HARRISON DR

FORT LEAVENWORTH KS 66027-2302
1 ARMY RSCH LABORATORY - HRED
(PDF) RDRL HRM AT J CHEN
12423 RESEARCH PKWY
ORLANDO FL 32826-3276
1 ARMY RSCH LABORATORY - HRED
(PDF) RDRL HRM AT C KORTENHAUS
12350 RESEARCH PKWY
ORLANDO FL 32826-3276

1 ARMY RSCH LABORATORY - HRED

(PDF) RDRL HRM CU B LUTAS-SPENCER

6501 E 11 MILE RD MS 284

BLDG 200A 2ND FL RM 2104

WARREN MI 48397-5000

1 ARMY RSCH LABORATORY - HRED

(PDF) FIRES CTR OF EXCELLENCE

FIELD ELEMENT

RDRL HRM AF C HERNANDEZ

3040 NW AUSTIN RD RM 221

FORT SILL OK 73503-9043

1 ARMY RSCH LABORATORY - HRED

(PDF) RDRL HRM AV W CULBERTSON

91012 STATION AVE

FORT HOOD TX 76544-5073

1 ARMY RSCH LABORATORY - HRED

(PDF) HUMAN RSRCH AND ENGRNG

DIRCTRT MCOE FIELD ELEMENT

RDRL HRM DW C CARSTENS

6450 WAY ST

BLDG 2839 RM 310

FORT BENNING GA 31905-5400

1 ARMY RSCH LABORATORY - HRED

(PDF) RDRL HRM DE A MARES

1733 PLEASONTON RD BOX 3

FORT BLISS TX 79916-6816

$\begin{array}{cl}8 & \text { ARMY RSCH LABORATORY - HRED } \\ \text { (PDF) } & \text { SIMULATION \& TRAINING } \\ & \text { TECHNOLOGY CENTER } \\ & \text { RDRL HRT } \quad \text { COL M CLARKE } \\ & \text { RDRL HRT I MARTINEZ } \\ & \text { RDRL HRT T } \quad \text { R SOTTILARE } \\ & \text { RDRL HRT B N FINKELSTEIN } \\ & \text { RDRL HRT G A RODRIGUEZ } \\ & \text { RDRL HRT I J HART }\end{array}$ 


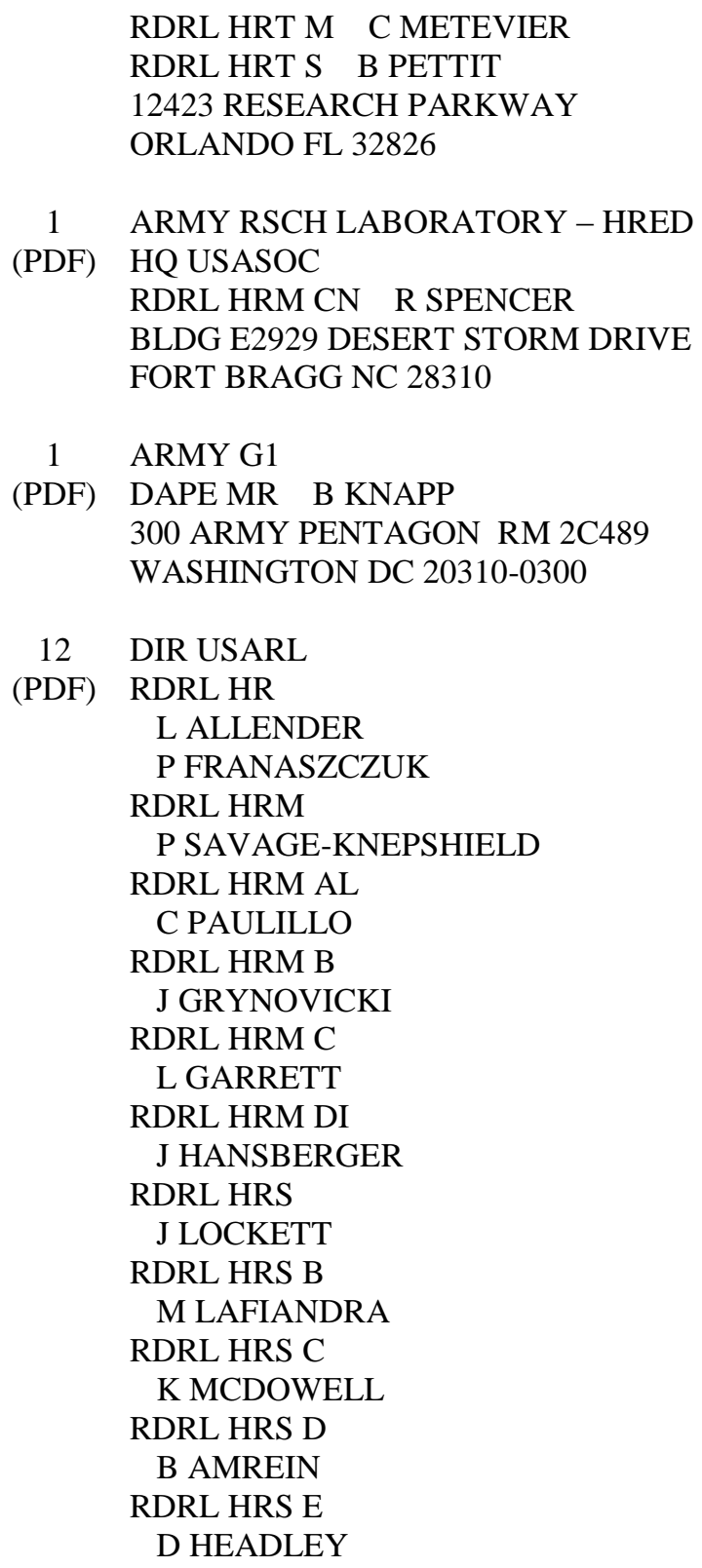


INTENTIONALLY LEFT BLANK. 